NBER WORKING PAPER SERIES

\title{
POSITIVE AND NORMATIVE IMPLICATIONS OF LIABILITY DOLLARIZATION FOR SUDDEN STOPS MODELS OF MACROPRUDENTIAL POLICY
}

\author{
Enrique G. Mendoza \\ Eugenio I. Rojas \\ Working Paper 24336 \\ http://www.nber.org/papers/w24336
NATIONAL BUREAU OF ECONOMIC RESEARCH
1050 Massachusetts Avenue
Cambridge, MA 02138
February 2018

This paper was prepared for the IMF's Eighteenth Jacques Polak Annual Research Conference. We would like to thank Cristina Arellano for her insightful discussion and conference participants for helpful comments. We are also grateful for comments and suggestions by Javier Bianchi, Emine Boz, Markus Brunnermeier, and Linda Tesar, and by participants at the 2018 AEA Annual Meetings, the XXIII Jornadas Anuales de Economía of the Central Bank of Uruguay, and the 2017 Workshop of the Financial Stability and Development Network of the IDB with the BISCCA. The views expressed herein are those of the authors and do not necessarily reflect the views of the National Bureau of Economic Research.

NBER working papers are circulated for discussion and comment purposes. They have not been peer-reviewed or been subject to the review by the NBER Board of Directors that accompanies official NBER publications.

(C) 2018 by Enrique G. Mendoza and Eugenio I. Rojas. All rights reserved. Short sections of text, not to exceed two paragraphs, may be quoted without explicit permission provided that full credit, including $\odot$ notice, is given to the source. 
Positive and Normative Implications of Liability Dollarization for Sudden Stops Models of Macroprudential Policy

Enrique G. Mendoza and Eugenio I. Rojas

NBER Working Paper No. 24336

February 2018

JEL No. E44,F34,F38,F41

\begin{abstract}
"Liability dollarization," namely intermediation of capital inflows in units of tradables into domestic loans in units of aggregate consumption, adds three important effects driven by realexchange-rate fluctuations that alter standard models of Sudden Stops significantly: Changes on the debt repayment burden, on the price of new debt, and on a risk-taking incentive (i.e. a negative premium on domestic debt). Under perfect foresight, the first effect makes Sudden Stops milder and multiple equilibria harder to obtain. The three effects add an "intermediation externality" to the macroprudential externality of standard models, which is present even without credit constraints. Optimal policy under commitment can be decentralized equally by taxing domestic credit or capital inflows, and hence capital controls as a separate instrument are not justified. This optimal policy is time-inconsistent and follows a complex, non-linear schedule. Quantitatively, an optimized pair of constant taxes on domestic debt and capital inflows makes crises slightly less likely and yields a small welfare gain, but other pairs reduce welfare sharply. For high effective debt taxes, capital controls and domestic debt taxes are again equivalent, and for low ones welfare is higher with higher taxes on domestic debt than on capital inflows.
\end{abstract}

\author{
Enrique G. Mendoza \\ Department of Economics \\ University of Pennsylvania \\ 3718 Locust Walk \\ Philadelphia, PA 19104 \\ and NBER \\ egme@ sas.upenn.edu \\ Eugenio I. Rojas \\ 160 McNeil Building \\ 3718 Locust Walk \\ Philadelphia, PA 19104 \\ eurojas@sas.upenn.edu
}




\section{Introduction}

Financial intermediation in emerging markets is characterized by what Calvo (2002) labeled "liability dollarization:" Banks intermediate capital inflows denominated in hard currencies (i.e. units of tradable goods) into domestic loans generally denominated in national currencies (i.e. units of national consumer prices). In South Korea or Mexico, for example, dollar inflows are lent out typically in domestic currency units, and the same happens also with Euro and Swiss Franc inflows in the emerging markets of Eastern Europe. A report by the Bank for International Settlements showed that in 2007, just before the global financial crisis, the ratio of foreign currency liabilities to total liabilities of commercial banks in emerging markets was about 40 percent in Latin America, 25 percent in Europe, and 15 percent in Asia, Africa and the Middle East, and the median ratio of external liabilities to gross loans in emerging markets was about 36 percent. ${ }^{1}$ Using IMF data, Eichengreen and Hausmann (1999) reported that in 1996, just before the Asian Crisis, the ratios of foreign liabilities to total assets in commercial banks ranged from 143 percent in Indonesia to 775 percent in Thailand.

The workhorse Sudden Stops model (SS) that has been widely used to study macroprudential policy in emerging markets to date abstracts from liability dollarization, because it is built upon the canonical Dependent Economy framework of International Macroeconomics. ${ }^{2}$ This framework includes income and consumption of tradable and nontradable goods but assumes that debt is denominated in units of tradables. SS models consider a stochastic variant of this setup in which domestic agents borrow by selling non-state-contingent bonds denominated in units of tradables, facing a credit constraint by which their debt cannot exceed a fraction of their income, part of which originates in the nontradables sector. ${ }^{3}$ The key element of SS models is that the collateral provided by nontradables income is valued at the market-determined relative price of nontradable goods relative to tradables, which yields two central implications: First, it introduces the Fisherian debtdeflation amplification mechanism, by which a binding collateral constraint triggers a feedback

\footnotetext{
${ }^{1}$ Capital Flows and Emerging Market Economies, CGFS Papers No. 33, Bank for International Settlements, January 2009.

${ }^{2}$ This framework originated in the seminal articles by Salter (1959), Swan (1960), and Díaz-Alejandro (1965).

${ }^{3}$ This setup originates in the work of Mendoza (2002). Studies that explore the models' normative implications, and in particular the implications for macroprudential policy, include Bianchi (2011), Benigno et al. (2016), Korinek (2011), Schmitt-Grohé and Uribe (2017), Bianchi et al. (2016), and Hernández and Mendoza (2017).
} 
mechanism linking reduced borrowing capacity, decreased consumption of tradable goods, and collapsing relative prices. Second, it introduces a "macroprudential" pecuniary externality, by which agents do not internalize in good times the effect of their borrowing decisions on relative prices and borrowing capacity in bad times when the credit constraint binds. These two features of the SS setup are related, because the magnitude of the pecuniary externality is determined by the size of the Fisherian amplification effect on prices (see Mendoza (2016)). Quantitative studies (e.g. Bianchi (2011), Bianchi et al. (2016)) have shown that both financial amplification and pecuniary externalities are large in SS models, and that optimal macroprudential policy reduces significantly the frequency and magnitude of Sudden Stops.

The assumption that domestic debt is in units of tradables simplifies theoretical and quantitative work with SS models significantly, but it also rules out liability dollarization by construction. Intermediaries in these models can be viewed as either domestic or international banks that raise funds by issuing liabilities in tradables units at the world real interest rate, and lend them to domestic agents in the same units and at that same rate but requiring them to post collateral. ${ }^{4}$ Interestingly, previous strands of the literature on emerging markets crises did introduce liability dollarization, particularly with the aim of studying aggregate implications of balance sheet effects and bank failures resulting from large devaluations (e.g. Choi and Cook (2004) and Céspedes et al. (2004)). This literature, however, did not focus on the implications of liability dollarization for private borrowers, which are the main focus of this study.

This paper shows that modeling the effects of liability dollarization on domestic borrowers alters significantly the results derived from SS models. In particular, we propose a model of Sudden Stops with liability dollarization (SSLD) in which intermediaries raise funds abroad in units of tradable goods but lend them out to domestic agents in units of the country's aggregate consumption good, represented by a CES composite of tradables and nontradables. As in standard SS models, the value of newly issued debt cannot exceed a fraction of the market value of income in units of tradables. In order to focus on the effects of liability dollarization on domestic borrowers, we assume that there are no other frictions in financial intermediation. Banks simply arbitrage the cost of raising

\footnotetext{
${ }^{4}$ This implies that the standard SS models of macroprudential policy do not justify the use of capital controls as an instrument to discriminate foreign $\mathrm{v}$. domestic credit.
} 
funds abroad v. the expected return of domestic loans. Bank liability is unlimited and there are no restrictions on equity issuance or dividends, so that bank failures do not play a role in crisis dynamics in the model.

Liability dollarization introduces three key effects that operate via real-exchange-rate movements: First, changes in the burden of repayment of outstanding debt, because ex-post realizations of high real exchange rates increase the domestic debtors' burden of repaying outstanding debt. Second, changes in the price of newly-issued domestic debt, because expectations of high future real exchange rates increase the price of newly issued debt, thus reducing ex-ante domestic real interest rates and strengthening borrowing incentives. Third, a risk-taking incentive in the form of a negative premium on the ex-ante domestic real interest rate, which results from the positive relationship between the real exchange rate and aggregate consumption. This induces a negative conditional co-variance between future marginal utility and future real exchange rates, which lowers the marginal cost of borrowing by domestic agents, also strengthening borrowing incentives. Moreover, these three effects interact with precautionary savings incentives by altering the volatility of income and the expected return on non-state-contingent domestic assets.

The three effects of liability dollarization produce major differences in the positive and normative predictions of the SSLD model relative to SS models. Regarding positive findings, we show that under perfect foresight, the debt-repayment-burden effect has two major implications: It makes Sudden Stops milder and multiple equilibria harder to obtain. Multiplicity requires significantly higher limits on debt-to-income ratios and income realizations that fall within a narrower range of relatively high values. These results are illustrated with quantitative examples for a widely used calibration for the case of Argentina borrowed from the work by Bianchi (2011), and also for a calibration similar to that used in the recent study on multiplicity in SS models by Schmitt-Grohé and Uribe (2018).

The normative analysis yields three important new results. First, by studying the optimal policy of a social planner acting with commitment under uncertainty, we identify a new pecuniary externality distorting the competitive equilibrium, which we label the "intermediation externality." This new externality co-exists with the macroprudential externality of SS models, and results 
from the planner's incentives to respond to the three effects of liability dollarization, which are not internalized by private borrowers because they operate through market-determined prices. Moreover, this externality is present even without credit constraints, and it can increase or reduce the social marginal cost of borrowing relative to its private counterpart. Hence, it can result in either under-borrowing or over-borrowing in the unregulated competitive equilibrium.

Second, we show that the optimal policy under commitment is time-inconsistent (i.e. lacks credibility). The planner has the incentive to pledge higher future consumption to sustain higher expected real exchange rates, and thus reduce ex-ante real interest rates at present. Once the future arrives, however, high real exchange rates are undesirable because of the higher debt repayment burden.

Third, the planner's optimal policy does not justify the use of capital controls, because it can be decentralized with an effective debt tax in which capital controls and taxes on domestic borrowing are equivalent. As in studies of optimal macroprudential policy in SS models, the planner is constrained-efficient in that it respects the pricing conditions of goods markets and financial intermediaries, and as result it cannot alter equilibrium allocations when the credit constraint binds. When it does not bind, it tackles the intermediation and macroprudential externalities by equating the social marginal cost of borrowing with its private counterpart, and this requires only an effective tax on debt. This debt tax can be managed equally with just taxes on capital inflows or on domestic credit, or any mix of both that supports the optimal effective debt tax rate.

Since the optimal policy lacks credibility and yields a complex, nonlinear schedule of effective debt taxes, we conduct a quantitative exploration of the effectiveness of a simple policy strategy that uses constant taxes on domestic debt and capital inflows, using again the calibration for Argentina taken from Bianchi (2011). In this analysis, the budgetary effects of both taxes are transferred to domestic private agents, which allows capital controls to prop up borrowing capacity when credit is constrained, and hence capital controls and domestic taxes need not be equivalent. The results show that the welfare-maximizing pair of constant taxes features a higher tax on domestic debt than on capital inflows, lowers the probability of Sudden Stops slightly, and yields a small welfare gain (while other tax pairs of similar magnitudes can reduce welfare sharply). Thus, under the best 
arrangement of constant taxes, the use of capital controls is justified, but capital inflows are taxed at a lower rate than domestic credit. Moreover, for tax pairs that support high effective debt taxes, capital controls and domestic debt taxes are again equivalent, and for other pairs welfare is higher with higher taxes on domestic debt than on capital inflows.

The rest of the paper proceeds as follows: Section 2 describes the model and characterizes the unregulated competitive equilibrium. Section 3 provides a theoretical and quantitative characterization of the differences between the SS model and SSLD models. Section 4 studies optimal financial policy of a social planner acting under commitment and conducts the quantitative analysis of constant taxes on domestic debt and capital inflows. Section 5 provides conclusions.

\section{Model Structure}

\subsection{Private agents}

Consider a small open economy where a representative agent consumes tradable goods $\left(c^{T}\right)$ and nontradable goods $\left(c^{N}\right)$. Preferences are given by a standard expected utility function with a constant-relative-risk-aversion (CRRA) period utility function that depends on a CES composite $\operatorname{good} c_{t}$ :

$$
\mathbb{E}_{0} \sum_{t=0}^{\infty} \beta^{t} u\left(c_{t}\right), \quad u\left(c_{t}\right)=\frac{c_{t}^{1-\gamma}}{1-\gamma}
$$

where:

$$
c_{t}=\left[\omega\left(c_{t}^{T}\right)^{-\eta}+(1-\omega)\left(c_{t}^{N}\right)^{-\eta}\right]^{-\frac{1}{\eta}}, \eta>-1, \omega \in(0,1) .
$$

$\mathbb{E}(\cdot)$ is the expectation operator, $\beta$ is the discount factor, $\gamma$ is the coefficient of relative risk aversion, and $1 /(1+\eta)$ is the elasticity of substitution between $c_{t}^{T}$ and $c_{t}^{N}$.

The relative price of nontradable goods in units of tradables is denoted $p_{t}^{N}$, and the relative price of the composite good $c_{t}$ in units of tradables is denoted $p_{t}^{c}$. Following standard practice (see Obstfeld and Rogoff (1996) p. 227), we apply the Duality Theory of consumer choice to characterize

this price as the price index that corresponds to the minimum expenditure $c_{t}^{T}+p_{t}^{N} c_{t}^{N}$ such that 
$c_{t}=1$. The price index is given by:

$$
p_{t}^{c}=\left[\omega^{\frac{1}{1+\eta}}+(1-\omega)^{\frac{1}{1+\eta}}\left(p_{t}^{N}\right)^{\frac{\eta}{1+\eta}}\right]^{\frac{1+\eta}{\eta}} .
$$

This relative price is also the economy's consumer-price-based measure of the real exchange rate, because foreign prices are normalized to 1 for simplicity and purchasing power parity in tradables holds, and hence the ratio of domestic to foreign consumer prices is the same as $p_{t}^{c}$. Notice also that $p_{t}^{c}$ is a monotonic, increasing function of $p_{t}^{N}$.

The agent receives a stochastic endowment of tradable goods $y_{t}^{T}$ and a fixed endowment of nontradable goods $\bar{y}^{N}$, and can trade non-state-contingent bonds $b_{t}^{c}$ denominated in units of $c_{t}$ at a price $q_{t}^{c}$ with financial intermediaries. Choosing the price of tradables as the numeraire, the agent's budget constraint is:

$$
q_{t}^{c} p_{t}^{c} b_{t+1}^{c}+c_{t}^{T}+p_{t}^{N} c_{t}^{N}=p_{t}^{c} b_{t}^{c}+y_{t}^{T}+p_{t}^{N} \bar{y}^{N}
$$

The left-hand-side of this expression shows the uses of the agent's income in units of tradables: purchases (sales) of bonds that require (generate) resources by the amount $q_{t}^{c} p_{t}^{c} b_{t+1}^{c}$ when $b_{t+1}^{c}>0$ $\left(b_{t+1}^{c}<0\right)$, plus total expenditures in consumption of tradables and nontradables. The righthand-side shows the sources of the agent's income: Income from maturing bond holdings $p_{t}^{c} b_{t}^{c}$ (or repayment of debt if $b_{t}^{c}<0$ ), the realization of the endowment of tradables $y_{t}^{T}$, and the value of the nontradables endowment in units of tradables $p_{t}^{N} \bar{y}^{N}$. The stochastic process of the tradable endowment follows a standard Markov process to be specified later.

Borrowing requires collateral in the same way as in standard SS models. Hence, only a fraction of the agent's income is pledgeable as collateral, and as a result, the agent cannot borrow more than a fraction $\kappa$ of total income in units of tradables:

$$
q_{t}^{c} p_{t}^{c} b_{t+1}^{c} \geq-\kappa\left(y_{t}^{T}+p_{t}^{N} \bar{y}^{N}\right)
$$

The representative agent chooses the stochastic sequences $\left\{c_{t}^{T}, c_{t}^{N}, b_{t+1}^{c}\right\}_{t \geq 0}$ to maximize (1) subject to (4) and (5), taking $b_{0}, \bar{y}^{N}$, and $\left\{p_{t}^{N}, p_{t}^{c}, q_{t}^{c}, y_{t}^{T}\right\}_{t \geq 0}$ as given. 


\subsection{Financial Intermediation}

We assume that there are deep-pockets, risk-neutral financial intermediaries who float bonds in international markets at a world-determined price $q^{*}$ (i.e. the inverse of the gross world real interest rate, $R^{*}$ which is kept constant for simplicity). They use the resources raised this way to fund purchases of the bonds that domestic agents issue in order to borrow. These intermediaries price domestic bonds according to this standard no-arbitrage condition:

$$
q_{t}^{c}=\frac{q^{*} \mathbb{E}_{t}\left[p_{t+1}^{c}\right]}{p_{t}^{c}}
$$

This price of domestic bonds issued at date $t$ has associated with it the ex-ante domestic real interest rate in units of $c$ given by $R_{t+1}^{c} \equiv 1 / q_{t}^{c}=\frac{R^{*} p_{t}^{c}}{\mathbb{E}_{t}\left[p_{t+1}^{c}\right]}$. This is the rate at which domestic bonds are contracted at date $t$, and the expected real exchange rate $\left(\mathbb{E}_{t}\left[p_{t+1}^{c}\right]\right)$ is one of its key determinants. Similarly, the ex-ante domestic real interest rate in units of tradables is defined as $R_{t+1}^{T} \equiv 1 /\left(q_{t}^{c} p_{t}^{c}\right)$, and it is also determined by the expected real exchange rate. In contrast, the value of the real exchange rate realized at $t+1\left(p_{t+1}^{c}\right)$ determines the ex-post real interest rate paid in units of tradables, which is given by $\tilde{R}_{t+1}^{T} \equiv \frac{R_{t+1}^{c} p_{t+1}^{c}}{p_{t}^{c}}$ with an associated implied price of $\tilde{q}_{t}^{T} \equiv \frac{q_{t}^{c} p_{t}^{c}}{p_{t+1}^{c}}$. As we show later, the difference between these ex-ante and ex-post interest rates plays a central role in driving the effects of liability dollarization.

Except for liability dollarization, this is a frictionless characterization of financial intermediation. Banks have unrestricted access to world capital markets, intermediation does not incur any costs other than the funding cost $R^{*}$, banks can pay negative dividends, and can always cover a shortfall between income from loans paid by domestic agents and repayment to foreign creditors with additional external borrowing. These assumptions are made so that we can isolate the effects of liability dollarization on the borrowers (i.e. the nonfinancial private sector), which have not been considered in the Sudden Stops literature before, and they also simplify greatly both the theoretical analysis and the numerical solution of the model. On the other hand, modifying the model to add intermediaries exposed to financial distress because of liability dollarization is of course an important item for further research. 


\section{Competitive Equilibrium \& Comparison with Standard Models}

The competitive equilibrium of the SSLD model is given by sequences of allocations $\left\{c_{t}^{T}, c_{t}^{N}, b_{t+1}^{c}\right\}_{t \geq 0}$,

and prices $\left\{p_{t}^{N}, p_{t}^{c}, q_{t}^{c}\right\}_{t \geq 0}$ that solve the optimization problem of the representative agent, satisfy the no-arbitrage condition of the financial intermediaries, and satisfy also the market-clearing condition of the nontradables sector $\left(c_{t}^{N}=\bar{y}^{N}\right)$ and the resource constraint of the tradables sector $\left(c_{t}^{T}=y_{t}^{T}-q_{t}^{c} p_{t}^{c} b_{t+1}^{c}+p_{t}^{c} b_{t}\right)$.

The equilibrium conditions are the following:

$$
\begin{gathered}
p_{t}^{N}=\left(\frac{1-\omega}{\omega}\right)\left(\frac{c_{t}^{T}}{c_{t}^{N}}\right)^{\eta+1} \\
u_{T}(t)=\beta \mathbb{E}_{t}\left[u_{T}(t+1) \tilde{R}_{t+1}^{T}\right]+\mu_{t} \\
q_{t}^{c} p_{t}^{c} b_{t+1}^{c} \geq-\kappa\left[y_{t}^{T}+p_{t}^{N} \bar{y}^{N}\right], \quad \text { with equality if } \mu_{t}>0 \\
q_{t}^{c} p_{t}^{c}=q^{*} \mathbb{E}_{t}\left[p_{t+1}^{c}\right] \\
c_{t}^{N}=\bar{y}^{N} \\
c_{t}^{T}=y_{t}^{T}-q_{t}^{c} p_{t}^{c} b_{t+1}^{c}+p_{t}^{c} b_{t}
\end{gathered}
$$

where $\mu_{t}$ is the non-negative Lagrange multiplier on the credit constraint, and $u_{T}(t) \equiv u^{\prime}\left(c_{t}\right) \partial c_{t} / \partial c_{t}^{T}$. Notice also two implications of these equilibrium conditions that will play an important role in the analysis that follows: First, (3), (7) and (11) imply that at equilibrium the price of nontradables and the price of consumption are increasing functions of tradables consumption, denoted $p^{N}\left(c_{t}^{T}\right)$ and $p^{c}\left(c_{t}^{T}\right)$ respectively. Second, if the credit constraint binds, $c_{t}^{T}$ is in fact independent of the value of $\mu_{t}$ and is given by the solutions to the following nonlinear equation in $c_{t}^{T}$ formed by conditions (7), (9) holding with equality, (11) and (12):

$$
c_{t}^{T}=(1+\kappa) y_{t}^{T}+\kappa p^{N}\left(c_{t}^{T}\right) \bar{y}^{N}+p^{c}\left(c_{t}^{T}\right) b_{t}^{c}
$$




\subsection{Comparison with Standard SS Models}

We compare the above equilibrium conditions with those pertaining to the standard model of Sudden Stops in order to isolate the effects of liability dollarization. ${ }^{5}$ In particular, since debt is non-state-contingent, liability dollarization introduces three key effects that result from the fact that borrowers are affected by real-exchange-rate fluctuations that induce movements in in ex-ante and ex-post real interest rates, and these effects are present even without the collateral constraint (although their magnitude does change with credit constraints).

1. Fluctuations in the debt repayment burden: At any date $t$, the burden of repaying debt $\left(b_{t}^{c}<0\right)$ contracted at $t-1$ is $p_{t}^{c} b_{t}^{c}$. Hence, variations in the realized real exchange rate alter the repayment burden. A real appreciation (depreciation) increases (reduces) it, inducing noninsurable fluctuations in income disposable for tradables consumption. This income effect can also be interpreted in terms of changes in the ex-post real interest rate in units of tradables. A real appreciation (depreciation) increases (reduces) the burden of debt repayment because it increases (reduces) the ex-post real interest rate. Moreover, these fluctuations increase effective income volatility and thus strengthen incentives for precautionary savings, which weaken incentives to borrow.

2. Fluctuations in the price of new domestic debt: The intermediaries' pricing condition (6) implies that, for a given world interest rate, the price of newly-issued domestic bonds in units of tradables $q_{t}^{c} p_{t}^{c}$ rises when the real exchange rate is expected to appreciate, which implies that the ex-ante domestic interest rate in units of tradables $R_{t+1}^{T}$ falls. Since we are studying an economy with debt $\left(b_{t+1}^{c}<0\right)$, this fall in the intertemporal relative price of $c_{t}^{T}$ triggers income and substitution effects pushing for debt to increase. The lower interest rate also weakens self-insurance incentives.

3. Risk-taking borrowing incentive: The marginal cost of borrowing faced by domestic agents falls because of the positive co-movement between consumption and the real exchange rate.

\footnotetext{
${ }^{5}$ The equilibrium conditions in the standard models differ in that $R^{*}$ replaces $\tilde{R}_{t+1}^{T}$ in condition (8), the terms $q_{t}^{c} p_{t}^{c} b_{t+1}^{c}$ and $p_{t}^{c} b_{t}^{c}$ are replaced with $q^{*} b_{t+1}$ and $b_{t}$ where $b_{t}$ are bonds in units of $c_{t}^{T}$, and condition (10) is removed.
} 
This result is evident if we re-write the Euler equation for domestic bonds as follows:

$$
u_{T}(t)=\beta R^{*} \mathbb{E}_{t}\left[u_{T}(t+1)\right]+\beta \operatorname{Cov}_{t}\left(u_{T}(t+1), \tilde{R}_{t+1}^{T}\right)+\mu_{t}
$$

The marginal cost of borrowing in the right-hand-side of this expression differs from the standard SS model with debt in units of tradables because of the term $\beta \operatorname{Cov}_{t}\left(u_{T}(t+1), \tilde{R}_{t+1}^{T}\right)$, which is negative because $u_{T}(t+1)$ is decreasing in $c_{t+1}^{T}$ and tradables consumption and the price of consumption are positively correlated. Hence, the marginal cost of borrowing is lower than in the standard model. In fact, since $c_{t+1}^{T}$ and $p_{t+1}^{c}$ are perfectly correlated, $\operatorname{Cov}_{t}\left(u_{T}(t+1), \tilde{R}_{t+1}^{T}\right)=\frac{-\sigma_{t}\left(u_{T}(t+1)\right) \sigma_{t}\left(p_{t+1}^{c}\right)}{q^{*} \mathbb{E}_{t}\left[p_{t+1}^{c}\right]}$, where $\sigma_{t}\left(u_{T}(t+1)\right)$ and $\sigma_{t}\left(p_{t+1}^{c}\right)$ are conditional standard deviations of marginal utility and the real exchange rate respectively. As a result, the risk-taking borrowing incentive strengthens when tradables marginal utility is more variable and/or the coefficient of variation of the real exchange rate $\left(\frac{\sigma t\left(p_{t+1}^{c}\right)}{\mathbb{E}_{t}\left[p_{t+1}^{c}\right]}\right)$ rises. This result also implies that, for given standard deviations of marginal utility and prices, the risk-taking incentive weakens when the real exchange rate is expected to appreciate. Hence, an expected real appreciation triggers opposing effects on borrowing incentives: It weakens the risk-taking incentive but strengthens the effect on the price of new debt.

Because of these three effects, Sudden Stops will differ in magnitude and frequency across SSLD and SS models with identical parameters, and they may occur at different levels of debt and income. If the constraint binds in both models for a given value of $y_{t}^{T}$, however, allocations and prices will differ only due to differences in the repayment burden of the outstanding debt. This is because, when the constraint binds, $c_{t}^{T}$ is determined by the non-linear equation obtained from combining the collateral and resource constraints, and this equation differs across the two models only because of the debt repayment terms. Still, along the equilibrium path of each model, the magnitude and frequency of Sudden Stops will differ depending on the outstanding debt $\left(b_{t}^{c}\right)$ and the size of income shocks $\left(y_{t}^{T}\right)$ needed to trigger the constraint in each economy. The outstanding debt that triggers Sudden Stops is endogenous and depends on the history of previous income shocks and optimal debt decisions, which differ in the two models because of the three effects described above. Similarly, the frequency of Sudden Stops will differ depending on the long-run probability with which each 
economy reaches states with enough debt to trigger a Sudden Stop.

SS models also have the property that while they can support unique equilibria, so that a particular sequence of income causes a shift from a unique unconstrained equilibrium to a unique constrained one, they can also support equilibrium multiplicity, so that for a given income level there can be both constrained and unconstrained equilibria and which one prevails depends on a "sunspot" variable (see, for example, Schmitt-Grohé and Uribe (2017, 2018)). Because multiplicity emerges due to the possibility of supporting more than one equilibrium when the credit constraint binds, due to the responses of collateral values and optimal debt choices, it is reasonable to expect that liability dollarization should also lead to differences across the SS and SSLD models in the conditions required for multiplicity and in the characteristics of multiple equilibria.

In the remainder of this Section, we compare the characteristics of Sudden Stops and multiple equilibria in the two models in a perfect-foresight environment, in which the solutions of the models can be fully characterized analytically. For a comparison of quantitative solutions of stochastic versions of the models see Mendoza and Rojas (2017).

\section{$3.2 \quad$ Perfect Foresight Analysis}

Under perfect foresight, ex-ante and ex-post real exchange rates and interest rates are the same. As a result, the Euler equation and resource constraint of the SSLD model can be rewritten as follows (assuming the standard no-Ponzi-game condition):

$$
\begin{gathered}
u_{T}(t)=\beta R^{*}\left[u_{T}(t+1)\right]+\mu_{t} \\
\sum_{t=0}^{\infty} R^{*-t} c_{t}^{T}=\sum_{t=0}^{\infty} R^{*-t} y_{t}^{T}+p_{0}^{c} b_{0}^{c}
\end{gathered}
$$

where $\sum_{t=0}^{\infty} R^{*-t} y_{t}^{T} \equiv W_{0}$ is the tradables non-financial wealth of the economy. These two conditions, together with (7), (9) and (11) characterize fully the SSLD equilibrium under perfect foresight. Following Mendoza (2005), we simplify the analysis by assuming that $\beta R^{*}=1, b_{0}^{c}<0$ (i.e. the economy starts with some debt), initial tradables income is lower than in the future so 
that agents would want to set $b_{1}^{c}<0$, and we study wealth-neutral shocks such that $y_{0}^{T}$ falls keeping $W_{0}$ constant, hence inducing agents to borrow more. For a sufficiently large shock, the collateral constraint binds, but for smaller shocks it does not.

If the collateral constraint does not bind and $\beta R^{*}=1$, tradables consumption is constant at the standard value of textbook models of consumption smoothing:

$$
\bar{c}^{T}=(1-\beta)\left(W_{0}+p_{0}^{c} b_{0}^{c}\right)
$$

It is straightforward to verify that the conditions that characterize the perfect-foresight equilibrium of the SS model are almost identical and yield an analogous solution for tradables consumption, except for one difference: In the term that represents financial wealth in the right-hand-side of (17), financial wealth is given by the term $b_{0}$ in the SS model (with bonds denominated in tradables), v. $p_{0}^{c} b_{0}^{c}$ in the SSLD model. These two terms will differ in general, because for given values of the exogenous initial conditions $b_{0}^{c}$ and $b_{0}$, the equilibrium value of the initial price $p_{0}^{c}$ determines whether the burden of repayment of the initial debt is higher in the SSLD or the SS case. However, taking the equilibrium price of nontradables $p^{N, S S}$ from an unconstrained solution of the SS model for a given $b_{0}$, we can compute the implied value of the consumption price index $p^{c, S S}$ and then define a threshold initial debt level in the SSLD model such that $\tilde{b}_{0}^{c} \equiv b_{0} / p^{c, S S}$. At this debt level, the SSLD and SS models yield identical unconstrained perfect-foresight equilibria because both financial and nonfinancial wealth are the same.

If $b_{0}^{c}<\tilde{b}_{0}^{c}\left(b_{0}^{c}>\tilde{b}_{0}^{c}\right)$, the SS model yields higher (lower) tradables consumption and prices than the SSLD model. ${ }^{6}$ Consumption rises (falls) by less than the reduction (increase) in debt because the increase (fall) in $p^{c}$ increases (reduces) the debt repayment burden and hence offsets some of the effect of the lower (higher) debt. Because of perfect foresight, the effects of liability dollarization operating via the price of newly issued debt and the risk-taking incentive are ruled out. Only the effect operating via the debt repayment burden is at work.

If the reduction in $y_{0}^{T}$ is sufficiently large to make the collateral constraint bind at $t=0$,

\footnotetext{
${ }^{6}$ Similarly, keeping $\tilde{b}_{0}^{c}$ and $b_{0}$ unchanged when making parametric changes that affect wealth (for example, temporary or permanent, unanticipated changes in the tradables income stream) results in different equilibria that depend on the changes in initial prices and debt repayment burden.
} 
a Sudden Stop occurs. Condition (12) implies that $c_{t}^{T}$ falls, because access to debt to sustain tradables consumption is constrained. Then it follows from condition (7) that $p_{t}^{N}$ falls to clear the nontradables market. This generates a further tightening of the collateral constraint, because it reduces the value of collateral provided by the nontradables endowment in condition (9). Formally, the date- 0 allocations and prices are determined by condition (13). This condition is again almost the same that determines tradables consumption in a Sudden Stop in the SS model, except for the debt repayment term $p^{c}\left(c_{0}^{T}\right) b_{0}^{c}$, which in the SS model is just $b_{0}$. By the same argument as before, the Sudden Stop equilibrium prices of the SS model could be used to set the exogenous value of $b_{0}^{c}$ so as to make the SS and SSLD solutions the same. But to compare Sudden Stops across the two models, assume instead that the initial condition is set at the value $\tilde{b}_{0}^{c}$, which sustains identical unconstrained equilibria. In this case, the Sudden Stop equilibria of the two economies differ.

Figure 1 illustrates the determination of equilibria in both models in the $\left(c^{T}, p^{N}\right)$ space for a scenario in which the equilibria are unique, in a manner analogous to Figure 2 in Mendoza (2005). The $P P$ curve is the marginal rate of substitution in consumption of tradables and nontradables, which given isoelastic preferences and the constant endowment of nontradables yields a convex function that maps $c^{T}$ into $p^{N}$ (this curve is the same in the SS and SSLD models). The various BB curves show the value of $p^{N}$ that corresponds to a value of $c^{T}$ such that the collateral constraint holds with equality and the tradables resource constraint is satisfied (i.e. equation (13) solved for $p_{0}^{N}$ as a function of $c_{0}^{T}$ ), for the SS and SSLD models and for each under different values of $y_{0}^{T}$. In each case, equilibrium is reached where the $P P$ curve and the relevant BB curve intersect. 
Figure 1: Sudden Stops under Perfect Foresight: Unique Equilibria

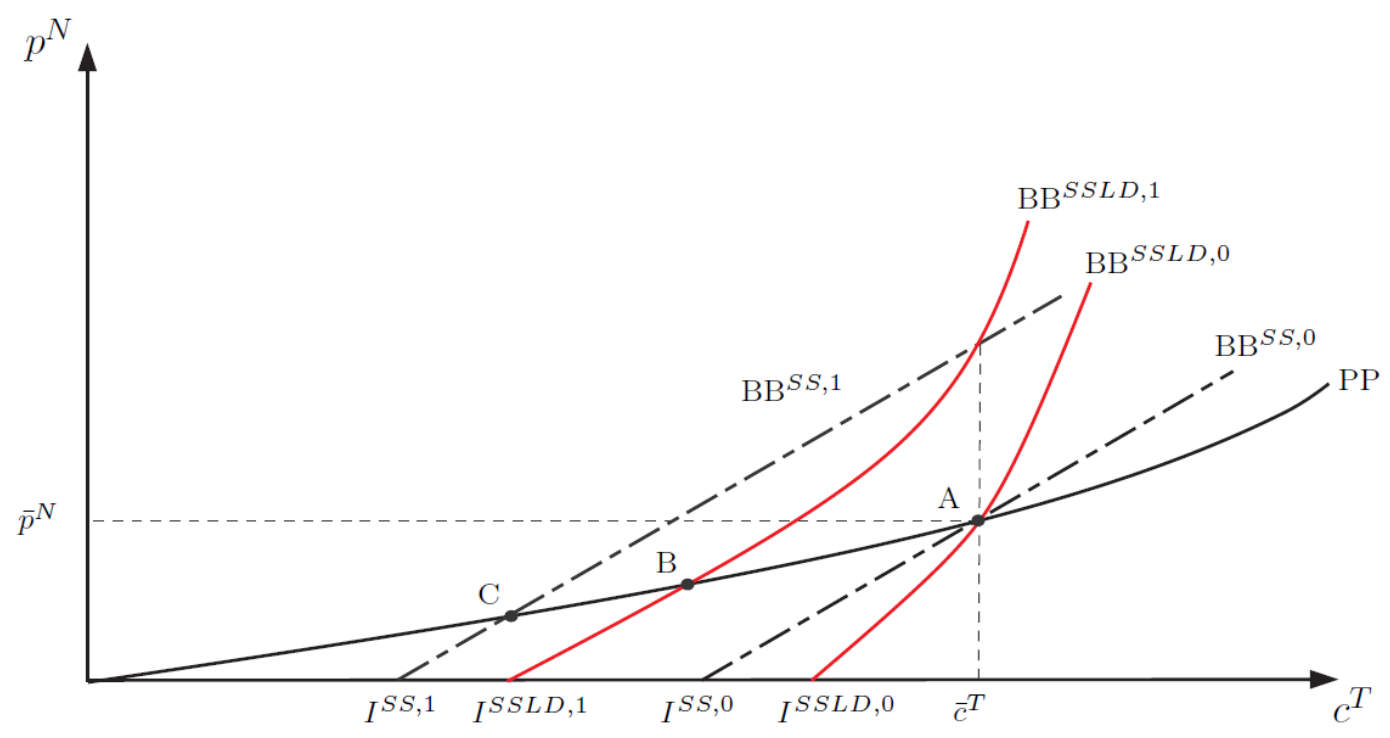

Mendoza (2005) showed that in the SS model, the $\mathrm{BB}^{S S}$ curves are increasing, linear functions of $c_{0}^{T}$ with an horizontal intercept given by $I^{S S} \equiv(1+\kappa) y_{0}^{T}+b_{0}$ and a slope of $m^{S S} \equiv 1 /\left(\kappa \bar{y}^{N}\right)$. For the SSLD model, we show in the Appendix that the $\mathrm{BB}^{S S L D}$ curves are also increasing in $c_{0}^{T}$ with an horizontal intercept given by $I^{S S L D} \equiv(1+\kappa) y_{0}^{T}+\omega^{1 / \eta} \tilde{b}_{0}^{c}$ and a slope of $m^{S S L D} \equiv$ $\left[1-p^{c \prime}(t) \tilde{b}_{0}^{c}\right] /\left(\kappa \bar{y}^{N}\right){ }^{7}$ Notice that again the difference between the SS and SSLD models is due to differences in the repayment burden of the initial debt. The term $\omega^{1 / \eta}$ in the intercept of the SSLD model is the lower bound of $p^{c}$ that is reached when $p^{N}=0$. Since at $\tilde{b}_{0}^{c}$ we have the same debt in units of tradables in the SS and SSLD models at the higher prices supported in the unconstrained equilibrium, the intercept of the SSLD model must be to the right of the one in the SS model (since the same debt is valued at the minimum price in the intercept of the SSLD model).

The $\mathrm{BB}^{S S, 0}, \mathrm{BB}^{S S L D, 0}$ curves are for a threshold income level $\hat{y}_{0}^{T}$ such that with a wealth-neutral shock that reduces date-0 income this much, the credit constraint allows for just enough debt to still support the unconstrained equilibrium. Hence, by construction (and again assuming the initial SSLD debt is $\tilde{b}_{0}^{c}$ ) these two $B B$ curves intersect $P P$ at point $\mathrm{A}$ and yield the same equilibrium

\footnotetext{
${ }^{7}$ As shown in the Appendix, the $\mathrm{BB}^{S S L D}$ curves are concave if the elasticity of substitution between $c^{T}$ and $c^{N}$ is greater or equal to 1 , convex if it is less or equal than $1 / 2$, and switch from concave to convex as $c^{T}$ rises if the elasticity is between $1 / 2$ and 1 . Under reasonable parameter values for emerging markets and any elasticity between 0 and 1 , however, $\mathrm{BB}^{S S L D}$ is either strictly convex or nearly linear with a slightly concave segment for very low $c^{T}$.
} 
values of $c^{T}$ and $p^{N}$ in the two models. The $\mathrm{BB}^{S S, 1}, \mathrm{BB}^{S S L D, 1}$ curves are for a lower $y_{0}^{T}$, which shifts the BB curves to the left, triggering the credit constraint and causing a Sudden Stop.

The main point of Figure 1 is to show that, when equilibria are unique, Sudden Stops under perfect foresight are milder in the SSLD model. The Sudden Stop equilibria are reached at points $\mathrm{B}$ and $\mathrm{C}$ for the SSLD and SS model respectively. Since the $\mathrm{BB}^{S S L D, 1}$ curve is always steeper than the $\mathrm{BB}^{S S, 1}$ curve and has a higher horizontal intercept, and since for given $y_{0}^{T}$ the two curves always intersect at point $\mathrm{A}, \mathrm{BB}^{S S L D, 1}$ must cut the $\mathrm{PP}$ curve to the right of where $\mathrm{BB}^{S S, 1}$ cuts it. $^{8}$ This implies that in the Sudden Stop of the SSLD economy, tradables consumption and relative prices are higher than in the SS economy. Both equilibria are Sudden Stops, because financial amplification via the deflation of the value of collateral causes a sudden drop from the unconstrained stationary consumption and prices at point A, but the drops in the SSLD model are always milder. The intuition is simple: In the SSLD economy, the fall in the real exchange rate associated with a Sudden Stop reduces $p_{0}^{c}$, and hence the burden of repaying $\tilde{b}_{0}^{c}$ in terms of tradable goods falls, providing additional resources for consumption of tradables. Notice that around point A the BB curves are steeper than the PP curve, which as we show below is a sufficient condition for the equilibria to be unique.

Figure 2 illustrates the equilibrium of both models when there are multiple equilibria. Intuitively, multiplicity can emerge if the parameters of the PP and BB curves are such that the curves intersect twice at values of $c^{T}$ less or equal than the unconstrained level. BB curves that are flatter than the PP curve around point A are necessary (but not sufficient) for this to happen. In the Figure, the $\mathrm{BB}$ curves for $\hat{y}_{0}^{T}$ are constructed in the same way as the $B B^{S S L D, 0}$ and $B B^{S S, 0}$ curves of the previous Figure: They correspond to a wealth-neutral shock such that the credit constraint is marginally binding (i.e. it can sustain at most the same amount of debt as in the unconstrained equilibrium) assuming again that the initial debt of the SSLD economy is set at $\tilde{b}_{0}^{c}$. Hence, point A has the same meaning as before. It shows the unconstrained stationary equilibrium that is identical in the SSLD and SS economies. The curvature and slope of the PP and BB curves has changed, and in particular the BB curves are significantly flatter. As a result, at an initial income of $\hat{y}_{0}^{T}$, the SS and SSLD economies now have two equilibrium solutions each: The unconstrained outcome at

\footnotetext{
${ }^{8}$ The fact that $p^{c \prime}(t) \tilde{b}_{0}^{c}<0$ implies that $m^{S S L D}>m^{S S}$, and the fact that $\omega^{1 / \eta} \tilde{b}_{0}^{c}<b_{0}$ implies that $I^{S S L D}>I^{S S}$.
} 
point A and the Sudden Stop outcomes (point B for the SS economy and C for the SSLD economy).

Figure 2: Multiple Equilibria under Perfect Foresight

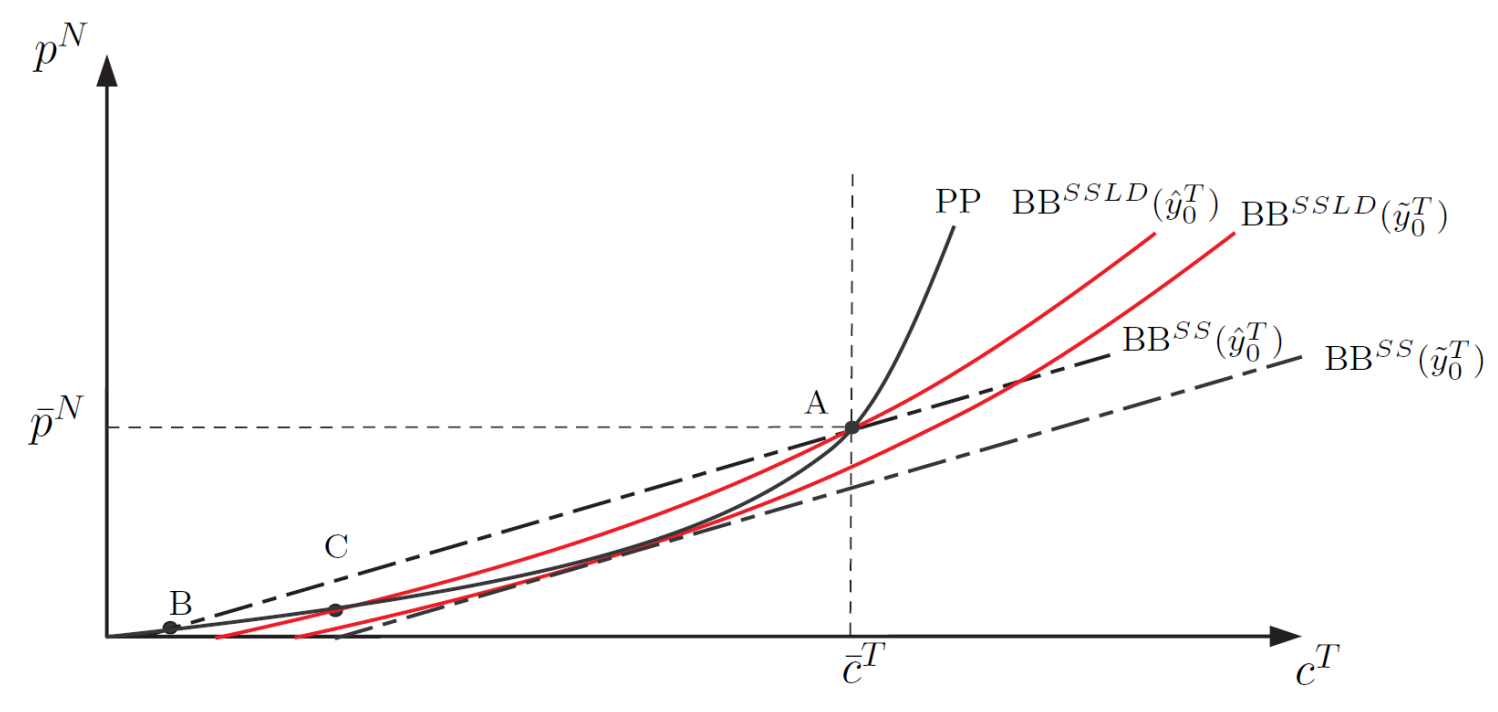

BB curves flatter than the PP curve around point A are not sufficient for equilibrium multiplicity because this also depends on the value of $y_{0}^{T}$. In the Figure, for $y_{0}^{T}<\hat{y}_{0}^{T}$, the BB curves shift to the left and only the Sudden Stops equilibrium survives (the unconstrained equilibrium is no longer attainable, just as in the case of unique Sudden Stop equilibria). When $y_{0}^{T}=\hat{y}_{0}^{T}$, we have the two equilibria as explained above. For $y_{0}^{T}>\hat{y}_{0}^{T}$, the BB curves shift to the right and three equilibria exist, because there would be two intersections with PP to the left of $\mathrm{A}$, plus the unconstrained equilibrium is also attainable since income exceeds $\hat{y}_{0}^{T}$. In contrast, when the BB curves are steeper than $\mathrm{PP}$ at point $\mathrm{A}$, the unconstrained equilibrium is the unique equilibrium for any income higher than $\hat{y}_{0}^{T}$. As $y_{0}^{T}$ continues to rise, however, $y_{0}^{T}$ reaches a threshold value $\tilde{y}_{0}^{T}$, different in the two models, at which once again the unconstrained equilibrium and only one Sudden Stop equilibrium are possible (see Figure 2), and for $y_{0}^{T}>\tilde{y}_{0}^{T}$ multiplicity disappears and only the unconstrained equilibrium survives, because the BB curves shift to the right enough to never intersect with PP. ${ }^{9}$

It follows from the above discussion that equilibrium multiplicity requires (a) BB curves flatter than PP around point $\mathrm{A}$, and (b) wealth-neutral income shocks such that $\hat{y}_{0}^{T} \leq y_{0}^{T} \leq \tilde{y}_{0}^{T}$. As we explain next, equilibrium multiplicity is harder to obtain in the SSLD model because, for the same parameter values and initial conditions, multiplicity requires higher values of $\kappa$ and narrower

\footnotetext{
${ }^{9} \tilde{y}^{T}$ is the income level that makes the $\mathrm{BB}$ curves tangent to the PP curve, which is different for the two models.
} 
income intervals.

Condition (a) can be formalized as follows: $A B B$ curve steeper than the PP curve around $\bar{c}^{T}$ is a sufficiency condition for a unique equilibrium when a Sudden Stop occurs. Since the PP curve is given by condition (7), its slope can be expressed as $\frac{(1+\eta) p_{t}^{N}}{c_{t}^{T}}$, which at the common unconstrained equilibrium of the two models equals $\frac{(1+\eta) \bar{p}^{N}}{\bar{c}^{T}}$. Consider next the slope of the BB curve in the SS model, which is $1 /\left(\kappa \bar{y}^{N}\right)$. It follows from equating these two slopes that the threshold value of $\kappa$ that guarantees a unique equilibrium in the SS model is $\hat{\kappa}^{S S}=\frac{\bar{c}^{T}}{(1+\eta) \bar{p}^{N} \bar{y}^{N}}$. Any $\kappa$ lower than this implies that Sudden Stop equilibria for any $y_{0}^{T} \leq \hat{y}_{0}^{T}$ are unique. This condition is the same one derived in Mendoza (2005).

The slope of BB in the SSLD model is $\frac{1-p_{0}^{c} b_{0}^{c}}{\kappa \bar{y}^{N}}$, and hence the threshold value of $\kappa$ for uniqueness of Sudden Stop equilibria under liability dollarization is $\hat{\kappa}^{S S L D}=\frac{\bar{c}^{T}\left(1-\bar{p}^{c} b_{0}^{c}\right)}{(1+\eta) \bar{p}^{N} \bar{y}^{N}}$. However, since we are assuming that the initial debt of the SSLD model is the value $\tilde{b}_{0}^{c}$ that supports the same unconstrained equilibria in both models, it follows that $\hat{\kappa}^{S S L D}=\hat{\kappa}^{S S}\left(1-\bar{p}^{c} \tilde{b}_{0}^{c}\right)=\kappa^{S S}\left(1-\xi_{p^{c}, c^{T}} \frac{\bar{p}^{c} \tilde{b}_{0}^{c}}{\bar{c}^{T}}\right)$, where $\xi_{p^{c}, c^{T}}$ is the elasticity of the CES price index with respect to tradables consumption, and is given by $\xi_{p^{c}, c^{T}}=\frac{1+\eta}{1+\left(\frac{\omega}{1-\omega}\right)^{\frac{1}{1+\eta}}\left(p^{N}\right)^{-\frac{\eta}{1+\eta}}}$. Hence, since $\tilde{b}_{0}^{c}<0$ and $\xi_{p^{c}, c^{T}}>0$ because $\bar{p}^{c \prime}>0$, we obtain that $\hat{\kappa}^{S S L D}>\hat{\kappa}^{S S}$. Thus, for identical parameters and the same initial conditions, multiplicity is harder to find in the SSLD model because it maintains uniqueness at higher values of $\kappa$ (i.e. the range of values of $\kappa$ for which Sudden Stop equilibria are unique is larger in the SSLD model). Moreover, $\hat{\kappa}^{S S L D}$ exceeds $\hat{\kappa}^{S S}$ by a percentage given by the absolute value of $\xi_{p^{c}, c^{T}} \frac{\bar{p}^{c} \tilde{b}_{0}^{c}}{\bar{c}^{T}}$, which in turn depends on preference parameters and the values of $W_{0}, y_{0}^{T}$ and $\tilde{b}_{0}^{c}$.

If $\kappa \geq \hat{\kappa}^{S S L D}>\hat{\kappa}^{S S}$, it is possible to have multiple equilibria in both models, but as we explained earlier, this is only a necessary condition. Multiplicity needs also condition (b) requiring tradables income to be in the interval $\left[\hat{y}_{0}^{T}, \tilde{y}_{0}^{T}\right]$, where as noted above $\tilde{y}_{0}^{T}$ is different in the SS and SSLD models, while $\hat{y}_{0}^{T}$ is the same (because of the assumption that the initial debt of the SSLD model is $\left.\tilde{b}_{0}^{c}\right)$. Hence, assuming that $\kappa$ is high enough to support multiplicity, the difference in the width of this interval across the two models indicates the extent to which multiplicity is easier or harder to obtain in one model v. the other. A wider (narrower) interval for the SSLD model suggests that multiplicity is easier (harder) to obtain, although the deterministic nature of the analysis does not 
take into account the probability of tradables income falling into a particular interval. Visually, Figure 2 suggests that the multiplicity interval of tradables income is narrower for the SSLD model, but this is easier to illustrate with quantitative examples, as we show below.

This analysis of equilibrium multiplicity could also be framed in terms of the analysis conducted by Schmitt-Grohé and Uribe (2018) using the standard SS model. They derived a similar condition on a threshold value of $\kappa$ required for multiplicity in the SS model, and showed that multiplicity requires in addition that the initial debt $\left(-b_{0}\right)$ falls within an interval of relatively low values. The consistency of the two approaches follows from noticing that the parametric differences in initial debt keeping $y^{T}$ constant can be alternatively represented as parametric differences in $y^{T}$ keeping initial debt constant (i.e. capitalize the initial income differences into changes in initial debt). Hence, the interval of relatively low debt values that sustains multiplicity translates into an interval of relatively high income values. We used the latter approach here because it allows us to make Sudden Stop outcomes in the SS and SSLD models comparable by keeping the initial debt set at the value such that the unconstrained equilibria are the same.

\subsection{Quantitative Examples}

We examine next the results of quantitative examples that illustrate the main theoretical findings we have presented. In particular, we illustrate the characteristics of Sudden Stops in the SSLD economy, compare Sudden Stops between the SS and SSLD models when Sudden Stop equilibria are unique, and show that multiplicity is harder to obtain in the SSLD model. We set parameter values following the calibration proposed by Bianchi (2011), which was designed to match properties in annual data for Argentina. Since we solve for perfect-foresight equilibria, we ignore the parts of his calibration that relate to the stochastic processes of tradables and nontradables income, and set $\bar{y}^{N}=1$ for all $t$ and $y_{t}^{T}=1$ for $t>0$. Table 1 lists the parameter values. 
Table 1: Parameters

\begin{tabular}{cc}
\hline \hline Parameter & Value \\
\hline$\gamma$ & 2 \\
$\eta$ & 0.205 \\
$\omega$ & 0.31 \\
$\beta, q^{*}$ & 0.91 \\
$\bar{y}^{N}$ & 1.00 \\
\hline \hline
\end{tabular}

Bianchi (2011) set the coefficient of relative risk aversion to $\gamma=2$, a standard value in DSGE models. He also set $\eta=0.205$, so that the elasticity of substitution between tradables and nontradables $(1 /(1+\eta))$ is 0.83 , which is the upper bound of a range of existing estimates. This elasticity is key for determining the elasticities of both $p^{c}$ and $p^{N}$ to changes in sectoral consumption allocations, which play a central role in determining the effects of Sudden Stops and the magnitude of the externalities driving the design of optimal financial policy, as we show in the next Section. $\omega=0.31$ is set so as to match a tradables consumption share of 32 percent. Bianchi also set the discount factor to $\beta=0.91$, so that his stochastic SS model can match Argentina's average net foreign asset position-GDP ratio of -0.29 from the data constructed by Lane and Milesi-Ferretti (2001). We take this same value of $\beta$ and since we are assuming $\beta R^{*}=1$ this implies $q^{*}=1 / R^{*}=\beta$.

Given the above parameter values, and $y_{t}^{T}=1$ for all $t$, we solve for the unconstrained equilibrium of the SS model for a value of $b_{0}$ such that the initial net foreign asset position-GDP ratio $\left(b_{0} /\left(y_{0}^{T}+\bar{p}^{N} \bar{y}^{N}\right)\right)$ matches Argentina's average, which implies $b_{0}=-0.868$. Then, using the value of the consumption price index at this equilibrium, $p^{c, S S}$, we solve for $\tilde{b}_{0}^{c}=b_{0} / p^{c, S S}$, which is the initial condition for bonds in the SSLD model that supports the same unconstrained stationary equilibrium as the calibrated SS model. This guarantees that the initial net foreign asset position-GDP ratio of the SSLD model, which is given by $p_{0}^{c} \tilde{b}_{0}^{c} /\left(y_{0}^{T}+\bar{p}^{N} \bar{y}^{N}\right)$, is also -0.29 .

Consider next the wealth-neutral shocks to $y_{0}^{T}$ (which assume future tradables income changes as needed to keep $W_{0}$ unchanged). As $y_{0}^{T}$ falls agents borrow more (bond holdings fall) at $t=0$ in order to maintain the same unconstrained consumption stream. For a given value of $\kappa$, this new 
debt choice approaches the maximum allowed by the credit constraint $\left(-\kappa\left[y_{0}^{T}+p_{0}^{N} \bar{y}^{N}\right]\right)$ as initial income falls. As long as the constraint does not bind, the SS and SSLD economies stay at the unconstrained equilibrium, but when it binds the allocations and prices at date 0 move to a Sudden Stop equilibrium, which may or may not be unique as we showed earlier.

We study first the case in which Sudden Stop equilibria are unique in both economies. To this end, we set $\kappa=0.29$ and solve for the equilibria of the two models for wealth-neutral income shocks in the interval $(0.85,1)$. Figure 3 presents the results for the SSLD economy as percent deviations from the unconstrained equilibrium, and shows also results for a hypothetical scenario in which $p^{c}$ and $p^{N}$ are kept fixed at the unconstrained levels.

When income is sufficiently high (for $y_{0}^{T}$ near 1 ), the credit constraint does not bind and therefore the plots show zero deviations from the unconstrained equilibrium. As $y_{0}^{T}$ falls the constraint becomes binding triggering Sudden Stops, and the plots show that aggregate and tradables consumption, as well as the price of nontradables and the real exchange rate, display sizable declines. For example, for a 5 percent shock $\left(y_{0}^{T}=0.95\right), c_{0}$ and $c_{0}^{T}$ fall by 2 and 6.3 percent respectively, and $p_{0}^{N}$ and $p_{0}^{c}$ fall by 7.6 and 5.3 percent respectively, bond holdings in units of tradables rise 580 basis points and there is a current account reversal of 45 basis points.

The comparison of Sudden Stops vis-a-vis the scenario with constant prices helps illustrate the extent to which the Fisherian deflation effect from the credit constraint (reducing $c_{0}^{T}$ ) and the debtrepayment-burden effect from liability dollarization (increasing $c_{0}^{T}$ ) offset each other. Keeping prices constant removes both effects, so that the declines in consumption that result are driven only by the exogenous drop in income and the fall in the exogenous component of borrowing capacity $\left(\kappa y_{0}^{T}\right)$, which are at work in both scenarios. Hence, if the two effects were of equal magnitude (in absolute value), the results for the SSLD case and the smooth prices case would be identical. The fact that the latter yields slightly larger Sudden Stops indicates that in the results for the SSLD economy the deflation and repayment-burden effects nearly offset each other, but the latter is slightly larger (in absolute value). Hence, through the debt-repayment-burden effect, liability dollarization is providing a very good hedge against the loss of resources caused by the endogenous component of borrowing capacity $\left(\kappa p_{0}^{N} \bar{y}^{N}\right)$. This result may not hold for different parameterizations, and it 
will also fail more generally in stochastic SSLD models in which the new-debt-price and risk-taking incentive are also at work.

Figure 3: Sudden Stops in Response to Income Shocks in the SSLD Model
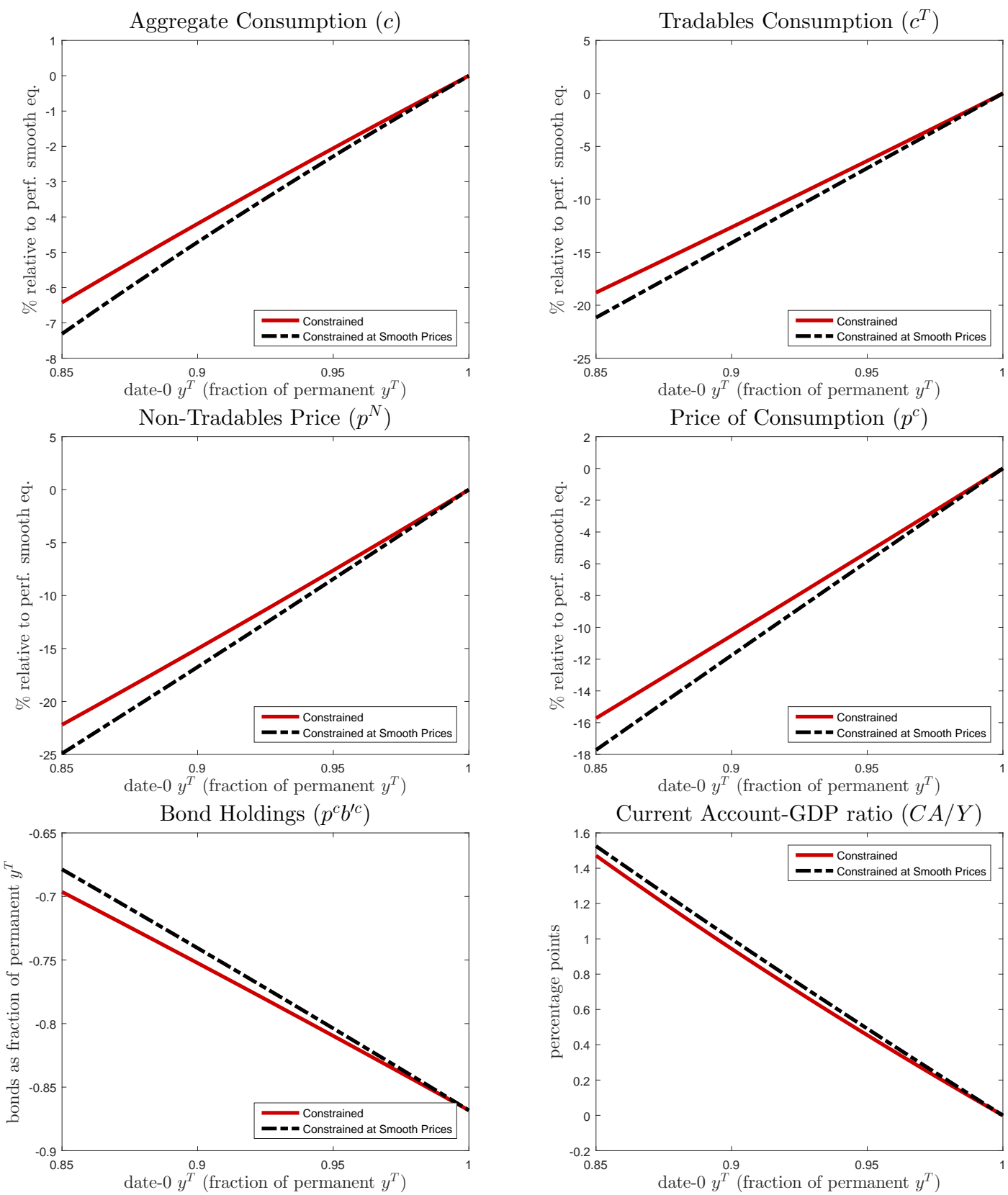

Figure 4 compares Sudden Stop equilibria between the SSLD and SS economies for $y_{0}^{T}=0.97$ (a 3 percent shock $)$ for values of $\kappa$ in the $(0.21,0.303)$ interval. Recall that both models have identical parameters and identical initial conditions, and hence the unconstrained solutions are identical. 
Figure 4: Sudden Stops in Response to Changes in $\kappa$ in the SS and SSLD Models
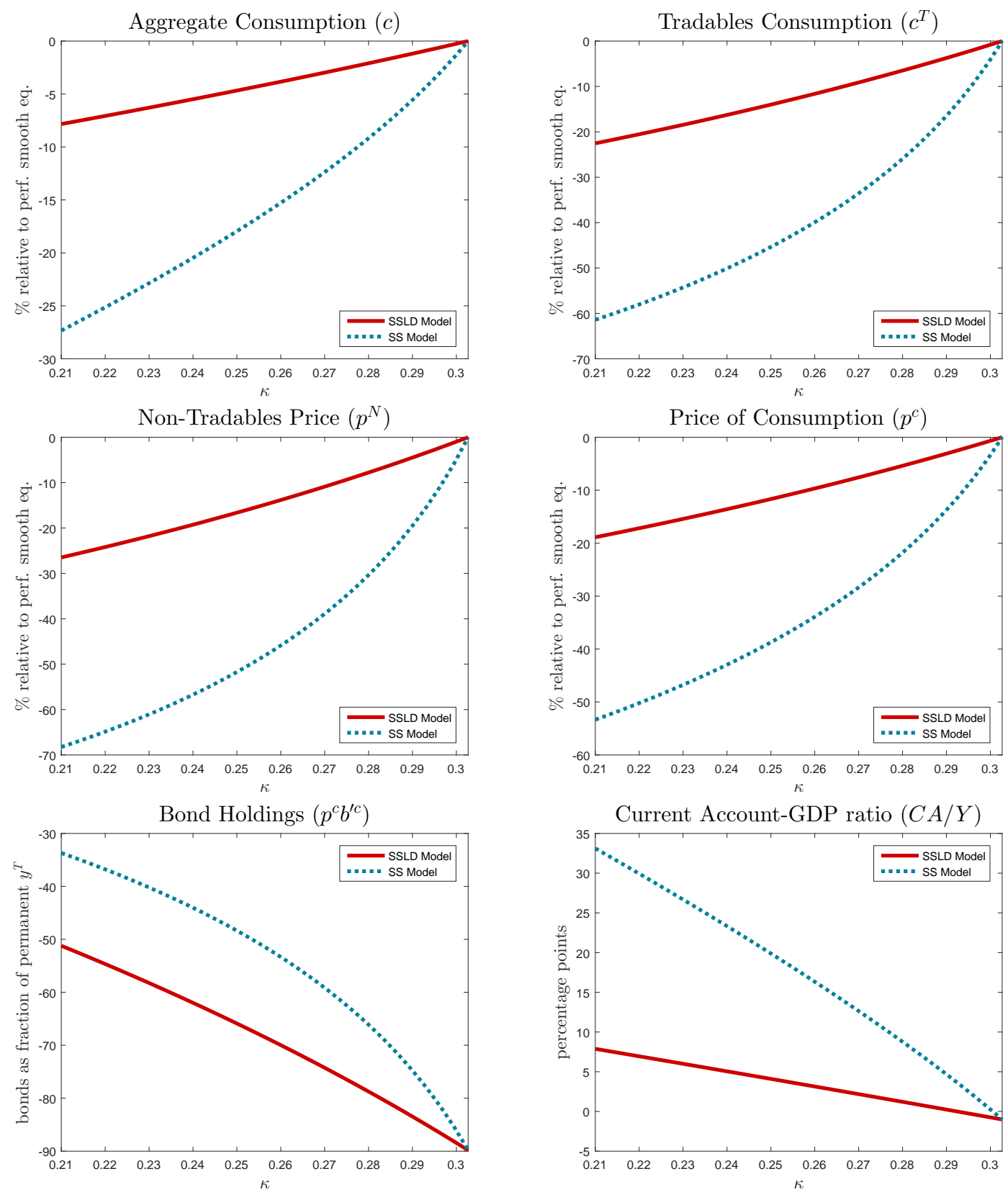

In line with the theoretical results derived earlier, the SSLD model always produces milder Sudden Stops, because of the debt-repayment-burden effect. For the upper bound of $\kappa$, the credit constraint does not bind, and hence both economies remain at the unconstrained equilibrium, which is identical between the two. As $\kappa$ decreases and borrowing capacity tightens, both economies move to unique Sudden Stop equilibria, but as the plots illustrate, the Sudden Stops of the SSLD economy 
are significantly smaller. For a drop in the debt-to-income limit of 5 percentage points, reducing $\kappa$ from 0.3 to 0.25 , the SS (SSLD) model produces declines in $c_{0}$ and $c_{0}^{T}$ of 18 and 45 (4.7 and 14) percent respectively, and drops in $p_{0}^{N}$ and $p_{0}^{c}$ of 51.7 and 38.7 (16.6 and 11.7) percent respectively. The current account rises by 20 percentage points of GDP in the SS model, compared with 4.1 in the SSLD model. ${ }^{10}$ The collapse in the real exchange rate $\left(p_{0}^{c}\right)$ moderates the Sudden Stops of the SSLD economy significantly, whereas in the SS economy its even larger collapse does not affect the debt repayment burden. Notice also that the gap between the equilibrium responses in both models widens as $\kappa$ decreases, indicating that the debt-repayment-burden effect works as an endogenous hedge that partially weakens Sudden Stops and by larger amounts for larger corrections in borrowing capacity.

Consider next the case of equilibrium multiplicity. Using the same parameter values as in the previous experiments, the threshold values of $\kappa$ that are necessary (but not sufficient) for multiple equilibria in each model are $\kappa^{S S}=0.38$ and $\kappa^{S S L D}=0.68$. Moreover, the factor by which the latter exceeds the former is $1-\xi_{p^{c}, c^{T}} \frac{\bar{p}^{c} \tilde{b}_{0}^{c}}{\bar{c}^{T}}=1.79$. Hence, the SSLD continues to yield unique Sudden Stop equilibria at $\kappa$ values up to roughly 1.8 times the threshold value of the SS model. Thus, the liability dollarization model requires significantly higher $\kappa$ values to produce multiplicity.

As explained earlier, in addition to $\kappa \geq \hat{\kappa}$, multiplicity requires income shocks to be within a particular range. Under the calibrated parameter values we proposed, however, the required income intervals do not intersect and hence multiplicity cannot be generated in both the SS and SSLD models simultaneously. Hence, in order to produce Sudden Stop outcomes with multiplicity we altered the model's parameters. We lowered the elasticity of substitution between $c^{T}$ and $c^{N}$ to $0.285(\eta=2.5)$, which is much lower than the range from literature estimates cited by Bianchi (2011), and halved the initial debt position (i.e. $\left.b_{0}^{c}=-0.149\right)$. With these parameter changes and setting $\kappa=0.45$ we can support multiple equilibria in both models, as shown in Figure 5 .

This Figure shows the equilibrium determination of the SS and SSLD models in our quantitative examples for two values of initial income, the threshold value $\hat{y}_{0}^{T}$ at which the credit constraint

\footnotetext{
${ }^{10}$ Mendoza and Rojas (2017) show that the finding that Sudden Stops are milder extends to quantitative comparisons of stochastic SS and SSLD models, in which the debt-price and risk-taking effects of liability dollarization are present, and that for the same calibration the SSLD model performs better at matching the observed empirical regularities of Sudden Stops.
} 
sustains just enough debt to support the unconstrained equilibrium, and the upper bound $\tilde{y}_{0}^{T}$ above which the only equilibrium the models can support is the unconstrained equilibrium. For each case, the Figure shows the corresponding BB curves of the SS and SSLD models, as well as the PP curve. As explained earlier, when income equals either $\hat{y}_{0}^{T}$ or $\tilde{y}_{0}^{T}$ the models support two equilibria, the unconstrained equilibrium and one Sudden Stop equilibrium, and for income levels inside this interval the models support three equilibria, the unconstrained one and two Sudden Stop ones. The value of $\hat{y}_{0}^{T}(0.397)$ is the same for the two models because we solve them with identical parameters and initial conditions. The values of $\tilde{y}_{0}^{T}$ are different because of the effects of liability dollarization, and they are $\tilde{y}^{T, S S}=0.627$, and $\tilde{y}^{T, S S L D}=0.463$ for the SS and SSLD model respectively. Hence, the range of income in which multiple equilibria exist under this calibration is much narrower in the SSLD model than in the SS model (about 1/3rd the size, $0.07 \mathrm{v}$. 0.23). Moreover, as noted earlier, multiplicity occurs when tradables income is "relatively high," in the sense of being (weakly) higher than the income level at which the credit constraint is only marginally binding. Hence, Sudden Stops triggered by multiplicity coincide with high income.

Figure 5: Multiple Equilibria in the SS and SSLD Models

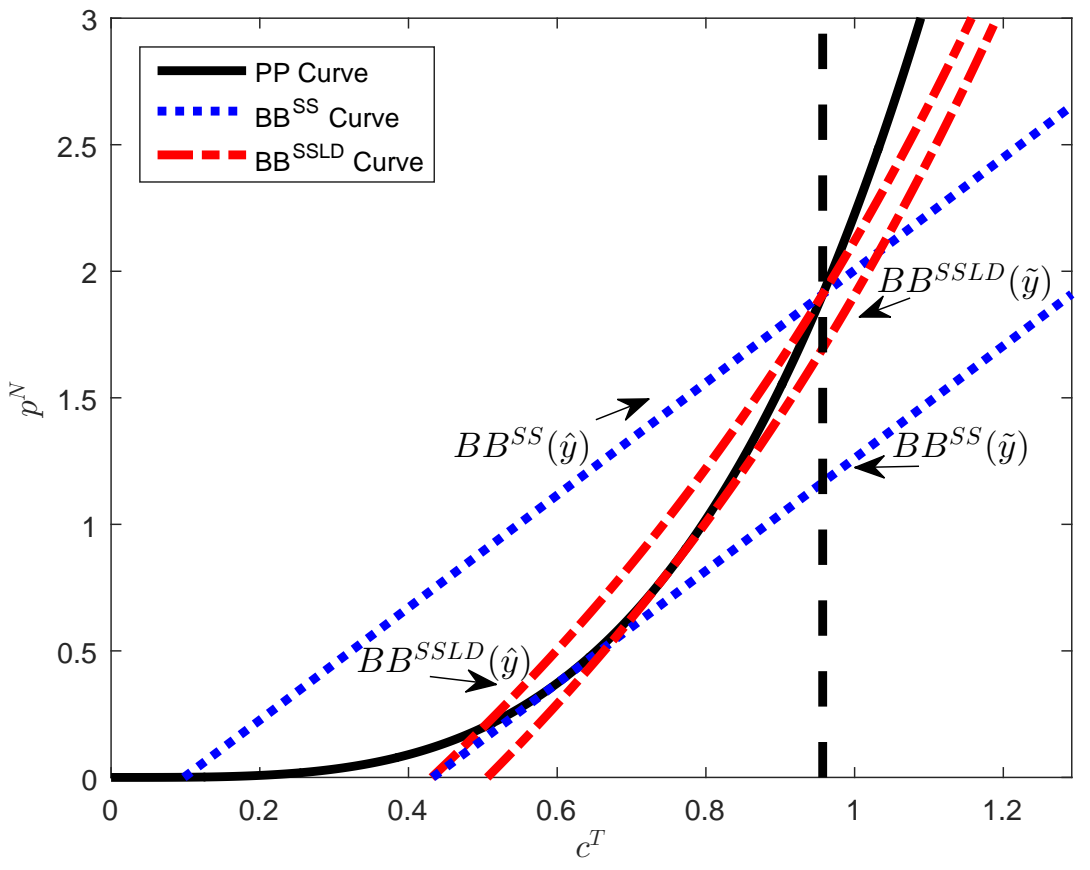

The difficulty in generating multiplicity with the SSLD model can be illustrated further by 
studying an alternative numerical example calibrated to match the scenario with multiplicity in the SS model studied in Schmitt-Grohé and Uribe (2018). Their calibration sets $\eta=1$, which implies an elasticity of substitution of 0.5 , still inside the range of empirical estimates but closer to the lower bound than in our baseline calibration, and $\omega=0.26$ (v. 0.31 in our experiments). Using the same initial debt we used here, these parameter values imply threshold values for $\kappa$ of $\kappa^{S S}=0.192$ and $\kappa^{S S L D}=0.456$. Hence, at their calibrated value of $\kappa=0.3$, there is multiplicity in the SS model, in line with their findings, but not in the SSLD model. Under liability dollarization, $\kappa$ would need to be nearly 2.4 times larger than the threshold of the SS economy, or 1.5 times their calibrated value, in order to be in the region in which multiplicity is possible.

\section{Normative Analysis}

In this Section, we study the normative implications of introducing liability dollarization in Sudden Stops models, focusing on unique equilibria for simplicity. Following Bianchi and Mendoza (2017), we characterize optimal financial policy following a primal approach by analyzing the allocations attainable to a social planner who chooses the debt of private agents under commitment subject to the resource, market-clearing, and collateral constraints, and letting goods markets and financial intermediaries operate competitively. ${ }^{11}$ We then explore the implications of this optimal policy for the design of domestic credit regulation (i.e. domestic debt taxes) v. capital controls. As we show below, the optimal policy is time-inconsistent, because of the planner's ability to affect the ex-ante domestic interest rate for debt contracted at date $t$ (or the expected real exchange rate) with the consumption of tradable goods planned for date $t+1$. Moreover, capital controls and debt taxes are equivalent, so under the optimal policy the SSLD model does not support the use of capital controls as a policy aimed at discriminating external v. domestic credit. Finally, since the optimal policy lacks credibility and follows a complex, nonlinear schedule, we study quantitatively the effectiveness of a simpler policy that sets time-invariant tax rates on domestic credit and capital inflows in a stochastic, infinite-horizon environment.

\footnotetext{
${ }^{11}$ The last assumption is equivalent to assuming that the planner cannot contract debt directly with foreign lenders in units of tradables, and instead borrows from the same intermediaries as private agents.
} 


\subsection{Optimal Policy under Commitment}

Assuming that the regulator chooses bond holdings for private agents, their optimization problem reduces to a simple static problem of choosing tradables and nontradables consumption subject to a budget constraint that includes the income from tradables and nontradables, and a lump-sum transfer (tax) from the planner that represents the amount of resources generated by borrowing (repaying). The private sector no longer chooses $b_{t+1}^{c}$ and does not face the collateral constraint. Hence, the first-order conditions of the agents' optimization problem no longer include the Euler equation for bonds (equation (8)) and the borrowing constraint (equation (9)), but the optimality condition for sectoral consumption allocation (equation (7)) still holds, since the market for nontradables still clears competitively. In addition, the no-arbitrage condition of financial intermediaries must also hold, because these intermediaries are also still operating competitively.

Using the nontradables market-clearing condition to substitute for $c_{t}^{N}$ and the intermediaries' noarbitrage condition to substitute for $q_{t}^{c} p_{t}^{c}$, the social planner's problem can be written as follows: ${ }^{12}$

$$
\begin{aligned}
& \max _{\left\{c_{t}^{T}, b_{t+1}^{c}\right\}} \mathbb{E}_{0} \sum_{t=0}^{\infty} \beta^{t} u\left(c_{t}\left(c_{t}^{T}, \bar{y}^{N}\right)\right) \\
& \text { s.t. } \\
& q^{*} \mathbb{E}_{t}\left[p^{c}\left(c_{t+1}^{T}\right)\right] b_{t+1}^{c}+c_{t}^{T}=p^{c}\left(c_{t}^{T}\right) b_{t}^{c}+y_{t}^{T} \quad \forall t \\
& q^{*} \mathbb{E}_{t}\left[p^{c}\left(c_{t+1}^{T}\right)\right] b_{t+1}^{c} \geq-\kappa\left(y_{t}^{T}+p^{N}\left(c_{t}^{T}\right) \bar{y}^{N}\right) \quad \forall t
\end{aligned}
$$

It is important to note that in this problem, as was the case in the competitive equilibrium, $c_{t}^{T}$ is independent of the value of $\mu_{t}$ when the constraint binds, and is determined by the same non-linear equation (13), which in this case follows from combining conditions (19) and (20).

As we show below, the solution to the above problem displays time-inconsistency. The key feature of the problem behind this result is that in the planner's resource and borrowing constraints, the real exchange rate expected for $t+1\left(\mathbb{E}_{t}\left[p^{c}\left(c_{t+1}^{T}\right)\right]\right)$ affects disposable resources and borrowing

\footnotetext{
${ }^{12}$ The planner's problem is written in short notation for simplicity. Given the Markov process of $y_{t}^{T}$, the expectations are taken over histories of realizations, with the date-t probability of a history $y^{T t}$ denoted by $\pi_{t}\left(y^{T t}\right)$ and the associated consumption and bonds allocations denoted by $c_{t}^{T}\left(y^{T t}\right)$ and $b_{t+1}^{c}\left(y^{T t}\right)$ respectively.
} 
capacity at date $t$. As a result, the planner's optimal plans for a given future date affect consumption allocations and borrowing capacity in the past.

The time-inconsistency result can be derived fomally by simplifying the planner's Euler equation for bonds to reduce it to the following expression: ${ }^{13}$

$$
\lambda_{t}=\frac{u_{T}(t)+\mu_{t} \kappa p^{N^{\prime}}(t) \bar{y}^{N}-p^{c^{\prime}}(t) b_{t}^{c}\left(\mathbb{E}_{t-1}\left[\lambda_{t}\right]+\frac{\operatorname{Cov}_{t-1}\left(\lambda_{t}, p^{c}(t)\right)}{\mathbb{E}_{t-1}\left[p^{c}(t)\right]}\right)}{1-p^{c \prime}(t) b_{t}^{c}}
$$

The planner's marginal utility of wealth at date $t\left(\lambda_{t}\right)$ depends on two terms determined at $t-1$. First, $\mathbb{E}_{t-1}\left(\lambda_{t}\right)$, which reflects the effect of changes in the amount of resources generated by debt contracted at $t-1$ on the marginal utility of wealth expected for date $t$. This is possible because, by affecting real exchange rate expectations, the planner alters $q_{t-1}^{c}$ and hence the amount of tradable goods that a given amount of debt issued at $t-1$ yields. Second, $\operatorname{Cov}_{t-1}\left(\lambda_{t}, p^{c}(t)\right) / \mathbb{E}_{t-1}\left[p^{c}(t)\right]$, which has a similar form as the private risk-taking incentive identified earlier in condition (14), except the planner's covariance is with respect to the social marginal utility of wealth one period ahead, instead of the marginal utility of tradables consumption. The private risk-taking incentive reduces the expected marginal cost of borrowing between $t$ and $t+1$. The planner, in contrast, considers how the covariance term alters the debt chosen at $t-1$ and thereby the debt repayment burden of date $t$. Through these two feedback effects, the planner's choice of consumption and debt at $t$ affects price expectations and the planner's covariance term at date $t-1$, which in turn alter $\lambda_{t}$ by affecting the debt chosen at $t-1$ and hence the burden of debt repayment at date $t$.

These feedback effects produce time-inconsistency because, as of a given date $t$, the planner has the incentive to pledge higher consumption at $t+1$, so that a higher expected real exchange rate props up $q_{t}^{c}$ and reduces the ex-ante real interest rate, strengthening borrowing incentives and borrowing capacity via the effects of liability dollarization discussed earlier. Ex-post, however, delivering on this pledge is suboptimal, because higher prices at $t+1$ imply a higher ex-post real interest rate, and thus a higher burden of debt repayment in that period. This time-inconsistency mechanism is at work regardless of whether the constraint binds or not, but it interacts with the constraint because by affecting borrowing incentives it affects the likelihood that the constraint can

\footnotetext{
${ }^{13}$ See Mendoza and Rojas (2017) for full details.
} 
bind at equilibrium. ${ }^{14}$

Bianchi and Mendoza (2017) obtained a similar result showing the time-inconsistency of optimal macroprudential policy under commitment in a model in which assets serve as collateral, but the mechanism driving the time-inconsistency that we described above is different. In Bianchi and Mendoza, the asset-pricing condition connecting current asset prices to future consumption leads the planner to prop up asset prices when the collateral constraint binds by pledging lower future consumption, which is not optimal to do ex-post. In contrast, in this model (and also in the SS model), since $p_{t}^{N}$ and $c_{t}^{T}$ are independent of the planner's future plans when the constraint binds at $t$, the planner cannot prop up the value of collateral with its future plans.

It is important to notice that time-inconsistency emerges here even though the collateral constraint is defined in terms of a limit on the debt-to-income ratio (a flow constraint), instead of a debtto-assets ratio (a stock constraint, as in Bianchi and Mendoza (2017)). Hence, time-inconsistency of optimal financial policy under commitment can exist in Fisherian models with either stock or flow collateral constraints. What is necessary is to have a vehicle that allows the planner to affect past prices and allocations, or borrowing capacity, with current consumption and debt choices. In contrast, optimal policy is time-consistent in standard SS models, because there is no vehicle for this to happen.

The planner's first-order conditions can be re-arranged to produce an alternative expression for the planner's Euler equation for bonds that equates the social marginal costs and benefits of borrowing, which is useful for characterizing the inefficiencies affecting the competitive equilibrium. As shown in Mendoza and Rojas (2017), the resulting expression is:

$$
\begin{aligned}
u_{T}(t)=\beta \mathbb{E}_{t}\left[\left[u_{T}(t+1)+\mu_{t+1} \kappa \bar{y}^{N} p^{N \prime}(t+1)\right] \tilde{R}_{t+1}^{T} \Psi(t+1)\right] & \\
& +\mu_{t}\left(\psi(t)-\kappa \bar{y}^{N} p^{N^{\prime}}(t)\right)
\end{aligned}
$$

where:

$$
\Psi(t+1) \equiv\left(\frac{\psi(t)}{\psi(t+1)}\right)
$$

\footnotetext{
${ }^{14}$ Notice that, when $\mu_{t}>0$, pledging higher $c_{t+1}^{T}$ could make the constraint less tight by increasing the price of bonds, but this does not generate additional resources for consumption, which are still be given by $-\kappa\left(y_{t}^{T}+p_{t}^{N} \bar{y}^{N}\right)$.
} 


$$
\psi(t) \equiv 1-p^{c \prime}(t) b_{t}^{c}+p^{c \prime}(t) b_{t}^{c}\left(\frac{\mathbb{E}_{t-1}\left[\lambda_{t}\right]}{\lambda_{t}}+\frac{\operatorname{Cov}_{t-1}\left(\lambda_{t}, p^{c}(t)\right)}{\lambda_{t} \mathbb{E}_{t-1}\left[p^{c}(t)\right]}\right)
$$

The comparable Euler equation in the competitive equilibrium is:

$$
u_{T}(t)=\beta \mathbb{E}_{t}\left[\tilde{R}_{t+1}^{T} u_{T}(t+1)\right]+\mu_{t}^{C E}
$$

where $\mu_{t}^{C E}$ denotes the multiplier of the collateral constraint in the competitive equilibrium.

Consider first the last terms in the right-hand-side of both Euler equations, which include the multipliers $\mu_{t}$ and $\mu_{t}^{C E}$. These terms are only present if the collateral constraint binds at date $t$, but in this case the specific values of the multipliers are irrelevant for the planner's allocations, because, as we noted earlier, $c_{t}^{T}$ is independent of $\mu_{t}$ and $\mu_{t}^{C E}$ when credit is constrained. Note, however, that allocations and prices will differ for the planner and the unregulated equilibrium, because by internalizing the externalities the planner will alter the likelihood of the constraint becoming binding and will generally arrive at states in which the constraint binds with different $b_{t}^{c}$.

Compare now the first terms in the right-hand-sides of the above Euler equations. These terms indicate that the product $\tilde{R}_{t+1}^{T} u_{T}(t+1)$ is part of both the social and private marginal costs of borrowing, but the social marginal cost includes other terms that reflect the effect of the pecuniary externalities at work in the model. The term $\mu_{t+1} \kappa p^{N^{\prime}}(t+1) \bar{y}^{N}$ is familiar from the standard SS models. It captures the macroprudential externality operating via the effect of the price of nontradables (i.e. the value of collateral) on borrowing capacity, and is strictly positive whenever states with $\mu_{t+1}>0$ have positive probability at $t+1$ as of date $t$, because $p^{N}$ is increasing in $c^{T}$. In states in which the collateral constraint is expected to bind, the social marginal cost of borrowing includes the shadow value of the loss in borrowing capacity caused by the fall in the price of nontradables if a Sudden Stop occurs, because the planner internalizes how the debt chosen at $t$ affects the size of the price drop at $t+1$. Hence, this macroprudential externality is an overborrowing externality, since it implies that the marginal cost of borrowing for private agents is lower than the social marginal cost.

The term $\Psi(t+1)$ captures a second pecuniary externality that is particular to the SSLD model, namely the intermediation externality. As the planner's Euler equation show, $\Psi(t+1)$ distorts the 
ex-post real interest rate paid in units of tradables. In turn, $\Psi(t+1)$ is a ratio composed of the intermediation externality's effects operating via the three mechanisms discussed earlier (repayment debt burden, price of newly issued debt, and risk-taking incentive) at date $t$ relative to $t+1$, which are summarized in the terms $\psi(t)$ and $\psi(t+1)$ respectively. Using the expression that defines $\psi(t)$, it follows that the effect operating via the debt repayment burden is captured by the term $1-p^{c \prime}(t) b_{t}^{c}$, which is strictly greater than 1 because $b_{t}^{c}<0$ and $p^{c \prime}(t)>0$. The planner internalizes that additional borrowing at date $t$ increases $p^{c}(t)$, which increases the burden of repaying outstanding debt. The effects operating via the price of new debt and the risk-taking incentive are captured by the term $\frac{p^{c \prime}(t) b_{t}^{c}}{\lambda_{t}}\left[\mathbb{E}_{t-1}\left(\lambda_{t}\right)+\frac{\operatorname{Cov}_{t-1}\left(\lambda_{t}, p^{c}(t)\right)}{\mathbb{E}_{t-1}\left[p^{c}(t)\right]}\right]$. This term reflects the fact that the planner internalizes the intermediaries' no-arbitrage condition, and hence takes into account how the social marginal cost of borrowing responds to the effect of changes in date- $t$ consumption on price expectations, the price of debt and incentives to borrow at $t-1$. In particular, the planner takes into account how these effects alter the amount of resources in units of tradables that debt contracted at $t-1$ generates and the social valuation of the risk-taking incentive at $t-1$.

If $\Psi(t+1)$ is greater (smaller) than 1 , the intermediation externality increases (reduces) the social marginal cost of borrowing relative to the private marginal cost of borrowing, and hence it operates as an overborrowing (underborrowing) externality. Unfortunately, while it is possible to show that $\psi(t)>0$ (see Mendoza and Rojas (2017)), the size of $\Psi(t+1)$ cannot be determined unambiguously. Using condition (24), however, we can infer that, everything else constant, $\Psi(t+1)$ is greater (smaller) than 1 if the planner's real-exchange-rate expectations (i.e. the ratio $\left.\mathbb{E}_{t}\left[p^{c}(t+1)\right] / \mathbb{E}_{t-1}\left[p^{c}(t)\right]\right)$ are increasing (decreasing) sufficiently. Hence, when the planner expects a sufficiently strong real appreciation, it faces an effective ex-post real interest rate higher than the one faced by private agents, and the intermediation externality operates as a second overborrowing externality. The opposite occurs when a sufficiently strong real depreciation is expected. Moreover, unlike the macroprudential externality that is only present when $\left.\mu_{t+1}\right)>0$ has positive probability as of date $t$, the intermediation externality is always present, regardless of whether the constraint is expected to bind or not (although the actual value of $\Psi(t+1)$ does depend on whether the constraint is expected to bind).

It is worth noting that the intermediation externality vanishes if we assume either complete 
asset markets or perfect foresight. Under perfect foresight, the covariance term in condition (24) vanishes and since $\mathbb{E}_{t-1}\left[\lambda_{t}\right]=\lambda_{t}$, it follows that $\psi(t)=1$ for all $t$ and hence $\Psi(t)=1 .{ }^{15}$ The same happens under complete markets because $\lambda_{t}$ becomes time- and state-invariant.

In order to decentralize the planner's allocations as a competitive equilibrium, we consider possibly using two policy instruments: Capital controls (i.e. taxes on the intermediaries' inflows of foreign capital) and domestic debt taxes (taxes on domestic borrowing). Capital controls are modeled as a $\operatorname{tax} \theta_{t}$ that raises the interest rate at which intermediaries borrow from abroad above $R^{*}$ (i.e. it lowers the price of bonds sold abroad below $q^{*}$ ). With this tax in place, the intermediaries' no-arbitrage condition becomes:

$$
q_{t}^{c}=\frac{q^{*}}{\left(1+\theta_{t}\right)} \frac{\mathbb{E}_{t}\left[p_{t+1}^{c}\right]}{p_{t}^{c}}
$$

The revenue generated by this tax is rebated to intermediaries as a lump-sum transfer, which can also be a lump-sum tax if $\theta_{t}<0$. Notice that the tax is known at the moment of issuing bonds, and is paid with the bond repayment.

The tax on domestic debt is denoted $\tau_{t}$. If this tax is used, the budget constraint of the representative agent becomes:

$$
q_{t}^{c} p_{t}^{c} b_{t+1}^{c}+c_{t}^{T}+p_{t}^{N} c_{t}^{N}=p_{t}^{c} b_{t}^{c}\left(1+\tau_{t}\right)+y_{t}^{T}+p_{t}^{N} \bar{y}^{N}+T_{t}
$$

where $T_{t}$ is a lump-sum rebate of the revenue generated by this tax (or a lump-sum tax if $\tau_{t}<0$ ).

If both taxes are used, the agent's Euler equation for bonds can be expressed as:

$$
u_{T}(t)=\left(1+\tau_{t}\right)\left(1+\theta_{t}\right) \beta \mathbb{E}_{t}\left[u_{T}(t+1) \tilde{R}_{t+1}^{T}\right]+\mu_{t}^{C E}
$$

This condition implies that, unless decentralizing socially optimal allocations requires different taxes on capital inflows and domestic debt for reasons other than distorting the private agents' intertemporal decision margin, taxing one is equivalent to taxing the other. What matters is the

\footnotetext{
${ }^{15}$ One effect of the intermediation externality does remain, and it operates via the debt repayment burden of the exogenous date- 0 debt $p_{0}^{c} b_{0}^{c}$. This can be seen in condition (24) because for $t=0$ there is no matching term $\mathbb{E}_{-1}\left[\lambda_{0}\right]$ to cancel the two terms with $p^{c \prime}(t) b_{t}^{c}$. Hence, the planner has the incentive to increase $p_{0}^{c}$ to reduce the debt repayment burden at $t=0$.
} 
combined effective tax rate $\left(1+\tau_{t}^{e f}\right) \equiv\left(1+\tau_{t}\right)\left(1+\theta_{t}\right)$, and the particular values of each tax are undetermined. One such instance is the standard SS model, in which intermediation is inessential and the only inefficiency affecting the unregulated decentralized equilibrium is the macroprudential externality leading agents to underestimate the social marginal cost of borrowing. In this case, the optimal policy can be implemented equally with only domestic debt taxes, only capital controls or any mix of both that yields the same $\tau_{t}^{e f}{ }^{16}$ Thus, the standard SS model of Sudden Stops does not provide a justification for capital controls as a policy to discriminate domestic $\mathrm{v}$. foreign credit flows.

The presence of the intermediation externality in the SSLD model is not sufficient to break the above equivalence result. The optimal policy under commitment still requires only an effective debt tax, and any combination of $\tau_{t}$ and $\theta_{t}$ that yields the same $\tau_{t}^{e f}$ yields a competitive equilibrium with identical allocations as those that solve the planner's problem. Hence, optimal policy under commitment in the SSLD model shares the property of the SS model that it does not justify the use of capital controls.

Since allocations and prices are independent of $\mu_{t}$ when the constraint binds at $t$, the relevant use of the tax is when $\mu_{t}=0$. In this case, the optimal tax is the one that equalizes the social and private marginal costs of borrowing given by the right-hand-sides of conditions (22) and (25):

$$
\tau_{t}^{e f}=\frac{\mathbb{E}_{t}\left[\left(u_{T}(t+1)+\mu_{t+1} \kappa \bar{y}^{N} p^{N \prime}(t+1)\right) \tilde{R}_{t+1}^{T} \Psi(t+1)\right]}{\mathbb{E}_{t}\left[\tilde{R}_{t+1}^{T} u_{T}(t+1)\right]}-1
$$

The numerator of this expression includes terms that correspond to the macroprudential and intermediation externalities. Since the intermediation externality can yield social marginal costs of borrowing higher or lower than their private counterparts, in principle the tax could be negative (i.e. a subsidy). In addition, unlike the optimal taxes of the SS model, in the SSLD model the taxes are used at date $t$ even if the collateral constraint has zero probability of becoming binding at $t+1$, as long as $\Psi(t+1) \neq 1$. Hence, it is not only a "macroprudential" tax, but a broader

\footnotetext{
${ }^{16}$ As explained earlier, intermediation in the SS setup can be interpreted as frictionless domestic banks that borrow and lend in tradables units, or as the nonfinancial private sector borrowing directly from abroad. Either way, the optimal policy needs to tackle only the inefficiency driving a wedge between the social and private marginal costs of domestic borrowing, and hence domestic debt taxes and capital controls are equivalent.
} 
financial policy aimed at tackling the intermediation externality. Moreover, this optimal tax policy inherits the time-inconsistency of the social planner's problem, and hence it lacks credibility. ${ }^{17}$

One important caveat of the above equivalence result is that it holds in part because of the stylized formulation of financial intermediation. If issuing domestic loans has a variable cost, for instance, the marginal cost of issuing domestic bonds would be subtracted from the right-hand-side of (26) and this would imply that setting $\theta_{t}$ at a given rate results in a larger increase in effective borrowing costs that setting $\tau_{t}$ at the same rate. Hence, extending the model to introduce realistic frictions in financial intermediation may not only introduce non-neutral balance sheet effects on banks as the real exchange rate moves, but may also provide a justification for capital controls.

If we switch to the standard SS model by imposing on the above optimal tax result the assumption that debt is issued in units of tradables, the expression reduces to $\tau_{t}^{e f}=\frac{\mathbb{E}_{t}\left[\mu_{t+1} \kappa \bar{y}^{N} p^{N^{\prime}}(t+1)\right]}{\mathbb{E}_{t}\left[u_{T}(t+1)\right]}$, which is the optimal debt tax of the standard SS model (e.g. Bianchi (2011), Bianchi et al. (2016)). The optimal tax of the SSLD model also preserves the result from the standard SS model that the value of the tax is indeterminate when $\mu_{t}>0$, because as explained above the planner's allocations are independent of $\mu_{t}$ when the collateral constraint binds. Therefore, any debt tax consistent with the collateral constraint being binding in the decentralized equilibrium with debt taxes can support the planner's allocations when $\mu_{t}>0$. In quantitative applications, the convention in the literature is to determine if a zero tax is consistent with this outcome, and if so the tax is assumed to be zero when the constraint binds.

\subsection{Quantitative Evaluation of Simple Rules for Debt Taxes \& Capital Controls}

The optimal financial policy under commitment has two shortcomings. First, it lacks credibility because of time inconsistency. Second, the optimal effective debt tax that would implement it would follow a non-linear schedule with complex variations over time and across states of nature, as dictated by the various terms in the optimal tax schedule defined in (29). In light of these

\footnotetext{
${ }^{17}$ See Mendoza and Rojas (2017) for an analysis of optimal time-consistent policy for a conditionally-efficient regulator that takes as given the pricing function of private debt of the unregulated competitive equilibrium. In this case, the equivalence breaks. Capital controls support the debt pricing function, effectively implementing a policy that targets the expected rate of real appreciation, and domestic debt taxes are set as needed to support the optimal $\tau_{t}^{e f}$ given the optimal $\theta_{t}$.
} 
shortcomings, we explore the effectiveness of a simpler policy strategy that consists of time-invariant taxes on domestic debt and capital inflows. In particular, we conduct a quantitative analysis of the extent to which this strategy can reduce the magnitude and severity of Sudden Stops and increase social welfare relative to the unregulated competitive equilibrium of the SSLD economy.

To conduct this analysis, we calibrate a stochastic version of the model and solve it numerically for the unregulated competitive equilibrium. Then we solve for competitive equilibria under different time-invariant values of $\tau$ and $\theta$, and implement an algorithm that searches for the welfaremaximizing pair of these constant taxes. ${ }^{18}$ We use a baseline calibration with most parameters set at the same values as in the perfect foresight analysis of Section 3.2. The only modifications are that we add the calibration of the stochastic process of the tradables endowment, for which we adopt again the one proposed by Bianchi (2011), and we reset the value of $R^{*}$ also to match Bianchi's $\left(R^{*}=1.04\right)$. The stochastic model requires $\beta R^{*}<1$ to have a well-defined stochastic steady state, because with $\beta R^{*}=1$ agents accumulate an infinitely large stock of precautionary savings. The Markov process for $y^{T}$ is constructed to approximate Bianchi's estimated AR(1) time-series process for the cyclical component of tradables GDP in Argentina, for which he obtained an autocorrelation coefficient $\rho_{y^{T}}=0.54$ and a standard deviation $\sigma_{y^{T}}=0.059$. We then used the quadrature method proposed by Tauchen and Hussey (1991) to construct a Markov chain with 9 realizations centered around $\mathbb{E}\left[y^{T}\right]=1$. We keep the value of $\kappa=0.29$, which is the same we used to generate Sudden Stops in the perfect foresight experiments. This $\kappa$ value also yields a frequency of Sudden Stops in the SSLD model that is close to empirical estimates (3.83 percent v. 3.32. percent in emerging markets data as reported in Mendoza (2010)), and lower than in Bianchi's SS model (5.5 percent).

When solving for competitive equilibria with constant taxes, we assume that the revenue (cost) generated by positive (negative) values of $\theta$ is rebated (charged) to private agents as part of their lump-sum transfers (taxes) $T_{t}$. We do this because, if they are passed on to intermediaries, the frictionless formulation of financial intermediation that we adopted renders a cut in $\theta$ equivalent to parametric increases in $q^{*}$, and hence subsidizing capital inflows is equivalent to lowering the world interest rate arbitrarily, making very large subsidies that can be painlessly paid for optimal. ${ }^{19}$

\footnotetext{
${ }^{18}$ We solve the competitive equilibrium with and without taxes using the same time-iteration algorithm with fixed grids as in Mendoza and Rojas (2017).

${ }^{19}$ If intermediaries pay the lump-sum taxes to finance these subsidies, the taxes cause a harmless fall in dividends,
} 
Under the above assumption, transfers to private agents are given by $T_{t}=-\tau p_{t}^{c} b_{t}^{c}-\theta q_{t}^{c} p_{t}^{c} b_{t+1}^{c}$, which together with the agents' budget constraint (27) and the pricing condition (26) yields the same resource constraint for tradables as in the equilibrium without taxes (12), thus removing the income effects induced by $\tau$ and $\theta$. In the equilibrium conditions that result, the two taxes appear as before in the Euler equation for bonds forming the wedge that defines $\tau^{e f}$, but now $\theta$ also appears in the collateral constraint as a term that contributes to make the constraint less tight. This is so because a higher $\theta$ moves borrowed resources further away from their constrained maximum, since it reduces $q_{t}^{c} p_{t}^{c}$ (see eq. (26)), which increases $q_{t}^{c} p_{t}^{c} b_{t+1}^{c}$ for $b_{t+1}^{c}<0$. This effect can also be interpreted as if $\theta$ effectively increases the fraction of income pledgeable as collateral, since the collateral constraint can be re-written as $q^{*} \mathbb{E}_{t}\left(p_{t+1}^{c}\right) b_{t+1}^{c} \geq-\kappa(1+\theta)\left(y_{t}^{T}+p_{t}^{N} \bar{y}^{N}\right)$.

If follows from the above arguments that, if we remove the collateral constraint, capital controls and domestic debt taxes levied on an otherwise competitive economy are again equivalent. Only $\tau^{e f}$ matters, and decomposing it into $\tau$ and $\theta$ is irrelevant. If the collateral constraint is present and is occasionally binding (and under the assumption that the budgetary impact of the capital controls is allocated to private agents instead of banks), the equivalence breaks because $\theta$ has an effect separate from $\tau$ when the constraint binds: It increases (reduces) borrowing capacity as $\theta$ rises (falls). Hence, the regulator now has an instrument that can alter allocations when the constraint binds. If using it can increase social welfare, this can justify using capital controls as a policy specifically aimed at targeting capital inflows.

Two important caveats about this result: First, it does not necessarily follow that a policy of setting $\theta$ high enough for the constraint never to bind while keeping $\tau^{e f}$ at zero is the best policy. This is because the intermediation externality is present even when the constraint does not bind, and this can make a competitive equilibrium with some degree of credit frictions more desirable than one without credit constraints (i.e. welfare in an SSLD economy where the constraint never binds is not necessarily higher than one where it can bind, while in the SS model this is always the case). Second, the above result does not alter the result that the equivalence between capital

because there is no limit on bank liability and no constraint requiring bank dividends to be positive. Lowering $\theta$ so as to approach -1 would then be optimal, because while the subsidy-adjusted value of collateral $\left(-(1+\theta) \kappa\left(y_{t}^{T}+p_{t}^{N} \bar{y}^{N}\right)\right)$ allows only for an infinitesimally small amount of debt, the amount of resources in units of tradables that this debt generates $\left(-\left(q^{*} \mathbb{E}_{t}\left(p_{t+1}^{c}\right) /(1+\theta)\right) b_{t+1}^{c}\right)$ grows infinitely large. 
controls and domestic debt taxes holds for implementing the social planner's equilibrium under commitment, because the planner has no incentive to act when the constraint binds, since it cannot alter allocations. ${ }^{20}$

In the quantitative experiments we discuss next, $\tau$ and $\theta$ take possible values from discrete grids. We solve the tax-distorted competitive equilibrium of the SSLD model for each available pair $(\tau, \theta)$ and search for the pair that yields the largest welfare gains relative to the unregulated competitive equilibrium. These welfare gains are computed as compensating variations in consumption constant across dates and states of nature that equate expected lifetime utility in the competitive equilibrium with taxes with that in the unregulated competitive equilibrium.

Figure 6 shows three plots that illustrate the welfare effects of fixed taxes on domestic debt and capital flows. Panel (a) shows the welfare effects of varying $\tau$ in the $[0,0.06]$ interval for $\theta=[-0.02,-0.01,0.005,0.01,0.02]$ (where 0.005 is the value that maximizes welfare with respect to $\theta$ ). Panel (b) shows the welfare effects of varying $\theta$ in the $[-0.03,0.06]$ interval for $\tau=[0.01,0.02,0.03,0.04]$ (where 0.02 is the value that maximizes welfare with respect to $\tau$ ). Panel (c) uses the same data of Panel (a), but plotted as a function of the value of $\tau^{\text {ef }}$ corresponding to each $(\tau, \theta)$ pair.

To understand the intuition behind these plots, keep in mind that without policy intervention the economy is affected by the macroprudential and intermediation externalities. Constant taxes can in principle weaken these externalities, but nothing guarantees a welfare-increasing outcome for arbitrary $(\tau, \theta)$ pairs. Whether this is the case or not depends on the extent to which the distortions introduced by these taxes tackle the externalities $\mathrm{v}$. the costs of these distortions themselves.

The distortions that the constant taxes introduce are determined by the following effects. First, there are the two distortions evident from the optimality conditions mentioned earlier: 1) both higher $\tau$ or higher $\theta$ increase the effective real interest rate in the Euler equation for bonds, thus increasing the marginal cost of borrowing; 2) higher $\theta$ increases borrowing capacity by increasing the effective fraction of income pledgeable as collateral. There are also two precautionary-savings

\footnotetext{
${ }^{20}$ Intuitively, the planner acting under commitment is constrained-efficient in terms of being subject to the collateral constraint and the pricing conditions of goods and asset markets, and the latter in particular means the planner is committed not to distort the intermediaries no-arbitrage condition, which the ad-hoc constant $\theta$ distorts.
} 
Figure 6: Welfare Effects of Constant Taxes

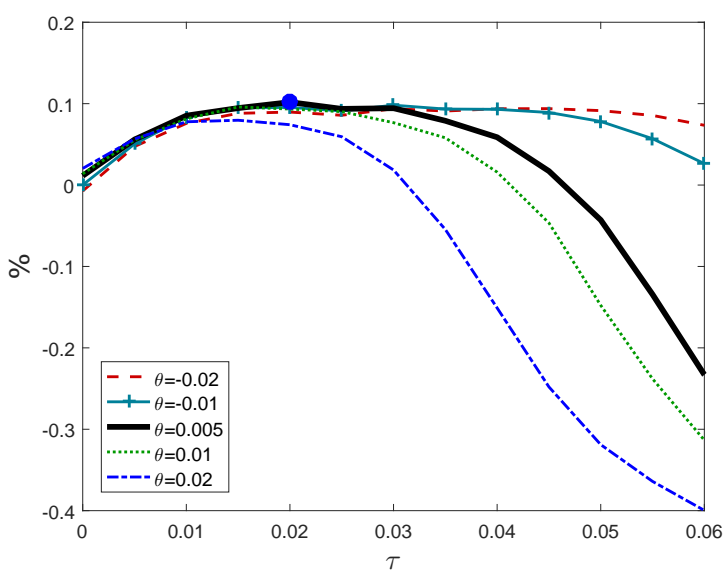

(a) Varying $\tau$ for given $\theta$

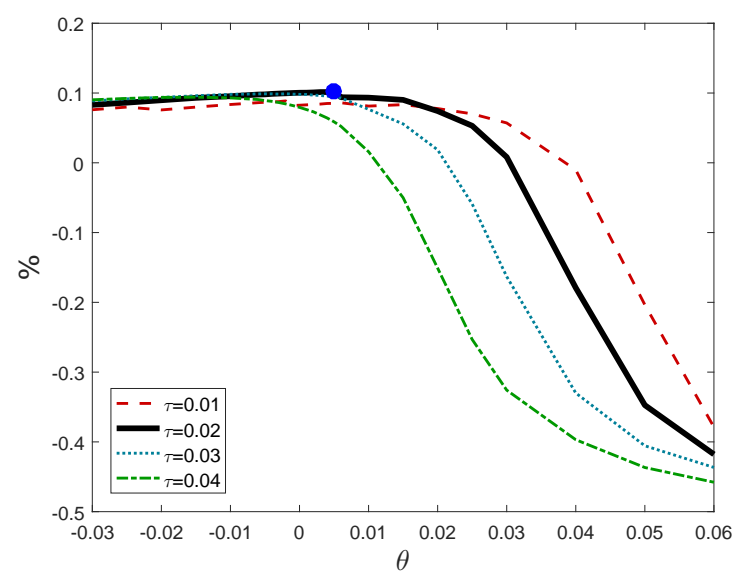

(b) Varying $\theta$ for given $\tau$

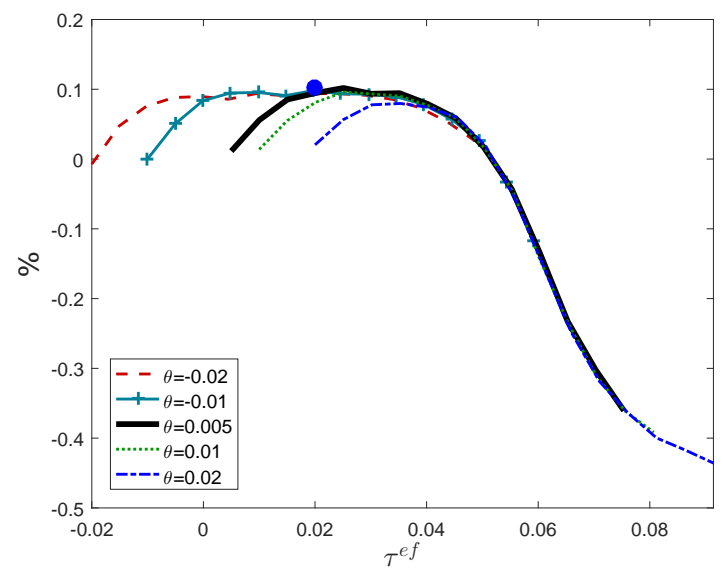

(c) Varying $\tau^{e f}$ for given $\theta$

Note: The circles identify the maximum value of welfare gains and the corresponding maximum $\tau$ and $\theta$ points for maximizing welfare gains across all $(\tau, \theta)$ pairs.

effects that are dynamic implications of the first two effects: 3) the interest-rate effect of higher $\theta$ or higher $\tau$ strengthens precautionary savings incentives; and 4) the collateral effect of higher $\theta$ reduces the need for precautionary savings. Finally, there is also a Sudden Stops effect: 5) as a result of the previous effects, changes in $\tau$ and/or $\theta$ affect the frequency and magnitude of financial crises, and these effects are non-monotonic (e.g if $\theta$ is so high that the constraint never binds, or is set at $\theta=-1$ so that no debt is allowed, the Fisherian deflation mechanism disappears).

When considering precautionary savings effects, it is worth recalling that the typical stationary 
asset demand curve of incomplete-markets models, which plots average bond holdings at different interest rates, is generally concave with a vertical asymptote at an ad-hoc debt limit and an horizontal asymptote where the interest rate equals the rate of time preference (see Ljungqvist and Sargent (2004)). This has two important implications for the effects of $\theta$ and $\tau$. First, because of the concavity, changes of equal size in $\theta$ or $\tau$ have much stronger effects on the average debt position around a high interest rate than a low one. Second, there is an asymmetry between the two instruments in how they alter the stationary debt position: changing $\tau$ or $\theta$ implies similar movements along the asset demand curve, but changing $\theta$ also alters credit limits and thus shifts the asset demand curve.

Panel (a) of Figure 6 shows that for $\tau<0.02$ welfare rises with $\tau$ and is about the same across the five values of $\theta$. In this region, a higher debt tax is beneficial because, via the effects mentioned above, it reduces the adverse effects of the macroprudential and intermediation externalities. The separate effect of $\theta$ on borrowing capacity does not make much difference, because although the lower values of $\theta$ reduce borrowing capacity, the higher debt taxes are already aiming to reduce debt in the economy. In contrast, as $\tau$ increases above 0.02 , welfare starts to decline for each value of $\theta$, as now taxing debt has a rapidly growing distortionary effect on borrowing decisions that exceeds the benefits of weakening the externalities. Moreover, welfare is much lower for higher $\theta$, because higher $\theta$ implies higher $\tau^{e f}$ for the same $\tau$, so the distortion on the borrowing decisions is larger. In addition, higher $\theta$ makes the distortion on the marginal cost of borrowing more painful, because it increases borrowing capacity which weakens incentives for precautionary savings (i.e. strengthens the desire to borrow).

For each curve corresponding to a given value of $\theta$ in Panel (a), there is a range of values of $\tau$ for which welfare is nearly independent of $\tau$. This is an implication of the shape of the welfare curves in Panel (b), which show that, for a given value of $\tau$, there is always a threshold value of $\theta$ below which welfare is only marginally increasing in $\theta$. In this region, the interest rate and borrowing capacity effects of $\theta$ push against each other, with low values of $\theta$ reducing the marginal cost of borrowing and precautionary savings because of the former, but also reducing borrowing capacity and increasing precautionary savings because of the latter. The net result is that welfare rises only slightly with $\theta$. On the other hand, for $\theta$ higher than the threshold value, welfare begins to fall 
sharply as $\theta$ rises, because now the marginal cost of borrowing is rising too much relative to the costs of the externalities, and the increased borrowing capacity is irrelevant. Note also that for a given $\theta$ in this region, welfare is sharply lower at higher $\tau$, because this implies higher $\tau^{e f}$ and hence a stronger distortionary effect of debt taxes.

Panel (c) of Figure 6 illustrates three important results of the regime with constant taxes. First, there is a region of tax pairs for which debt taxes and capital controls are equivalent, and hence only the effective debt tax matters. In particular, when the $\tau, \theta$ values yield $\tau^{e f} \geq 0.038$, a given $\tau^{e f}$ yields the same welfare regardless of the value of $\theta$. This is because at sufficiently high $\tau^{e f}$ incentives to borrow are weakened enough to make the effect of $\theta$ on borrowing capacity irrelevant, and as explained earlier, in the absence of this mechanism the two instruments are equivalent. But for $\tau^{e f}<0.038$ the equivalence breaks. For a given $\tau^{\text {ef }}$ in this region, welfare is lower at higher values of $\theta$. This is a key result, because it shows that when the two instruments are not equivalent, it is preferable to generate a given $\tau^{e f}$ with a mix that uses (weakly) lower capital controls, because in this region a higher borrowing capacity with a higher $\theta$ makes taxing debt more costly. Second, as in Panel (a), for each value of $\theta$ there is an interval of values of $\tau^{e f}$ that generates roughly similar welfare effects and this interval is wider for lower $\theta$, which is again due to the flat region of welfare effects identified in Panel (b). This result is important because it shows that, if the choice is only over constant taxes and $\theta$ is set relatively low, regulators have more "margin of error" for setting $\tau$ without reducing welfare sharply. Third, it is easy for constant taxes to produce outcomes that reduce welfare relative to the unregulated competitive equilibrium, by as much as as $0.45 \%$ for $\tau^{e f}=0.09$. Any $(\tau, \theta)$ pair that yields a value of $\tau^{e f}$ above 0.045 is worst than leaving the economy unregulated and fully exposed to Sudden Stops, and this is true for all the values of $\theta$. Considering in addition that, as noted below, even the welfare-maximizing constant taxes yield small welfare gains and modest declines in the frequency and severity of Sudden Stops, this result highlights the importance of careful quantitative evaluation of macro-oriented financial regulation.

The welfare-maximizing pair of tax rates is $\tau^{*}=0.02$ and $\theta^{*}=0.005$, which implies $\tau^{* e f}=0.025$ and yields a welfare gain of only 0.1 percent. ${ }^{21}$ Table 2 sheds light on the effectiveness of this

\footnotetext{
${ }^{21}$ This is only $1 / 5$ th the size of the gain that Mendoza and Rojas (2017) found for an optimal, time-consistent policy of time-varying tax rates.
} 
policy for reducing the magnitude and frequency of Sudden Stops by comparing key moments of the unregulated competitive equilibrium v. the equilibrium with the welfare-maximizing pair of taxes. The long-run averages of consumption and the debt ratio are about the same, the latter just a notch smaller with the constant taxes. Since mean consumption is about the same, we can infer that the differences in welfare are largely influenced by differences in how the macroprudential and intermediation externalities affect regular business cycles, the frequency and magnitude of Sudden Stops, and the frequency with which the collateral constraint binds (even without a Sudden Stop). ${ }^{22}$ With the constant taxes, the probability of the collateral constraint being binding falls by over 350 basis points (from 35.4 to 31.8 percent) and the probability of Sudden Stops falls by roughly 60 basis points (from 3.83 to 3.23 percent), but in fact when Sudden Stops do happen consumption falls slightly more.

Table 2: Effectiveness of Constant Taxes

\begin{tabular}{lcc}
\hline \hline Long-run Moments $^{1}$ & $(1)$ & $(2)$ \\
\hline & $\mathrm{DE}$ & $\mathrm{CT}$ \\
\hline Average $\left(P^{c} b^{c} / Y\right) \%$ & -29.41 & -29.07 \\
Welfare Gain $\%$ & $\mathrm{n} / \mathrm{a}$ & 0.10 \\
Prob. of Sudden Stops $\% \%$ & 3.83 & 3.23 \\
Prob $\left(\mu_{t}>0\right) \%$ & 35.38 & 31.84 \\
Domestic Debt Tax Rate $\tau \%$ & $\mathrm{n} / \mathrm{a}$ & 2.00 \\
Capital Inflows Tax Rate $\theta \%$ & $\mathrm{n} / \mathrm{a}$ & 0.50 \\
\hline Average $c$ & 0.989 & 0.989 \\
Average change of $c$ in Sudden Stops $\%$ & -4.60 & -4.87 \\
\hline \hline
\end{tabular}

${ }^{1}$ DE denotes the unregulated decentralized economy and CT the economy with constant taxes and capital controls.

${ }^{2}$ Welfare gains are computed as compensating variations in consumption constant across dates and states that equate welfare in the economy with regulation with that in the unregulated decentralized equilibrium. The welfare gain $W$ at state $\left(b^{c}, y^{T}\right)$ is given by $\left(1+W\left(b^{c}, y^{T}\right)\right)^{1-\sigma} V^{\mathrm{DE}}\left(b^{c}, y^{T}\right)=V^{i}\left(b^{c}, y^{T}\right)$. The long-run average is computed using the ergodic distribution of the unregulated economy. ${ }^{3}$ A Sudden Stop is defined as a period in which the constraint binds and the current account raises by more than two standard deviations in the ergodic distribution of the decentralized economy.

\footnotetext{
${ }^{22}$ As in the literature (see Mendoza (2010)), we define Sudden Stops as states in which the constraint binds and the current account increases by more than two standard deviations.
} 
Examining how the constant taxes affect Sudden Stop dynamics sheds more light on their effectiveness. To study Sudden Stop dynamics, we follow the same procedure as in Mendoza and Rojas (2017), which is based in generating a long time-series simulation of the economies with and without taxes, identifying Sudden Stop events in the simulated data of the current account, and constructing seven-year event windows centered on the date when Sudden Stops occur. Figure 7 shows Sudden Stop event windows for the model's key variables in the unregulated economy and in the economy with the welfare-maximizing pair of constant taxes.

This Figure shows that the constant-taxes regime does poorly in terms of macroeconomic performance when Sudden Stops hit (i.e. at $t=0$ ). Aggregate and tradables consumption, as well as the relative price of nontradables and the consumption prince index, show slightly larger declines with the constant taxes in place. The current account reversal and the ex-ante and ex-post prices of domestic bonds are about the same with or without taxes. In contrast, the expected real exchange rate is significantly less volatile, but this is a straightforward implication of the capital controls and the no-arbitrage condition of intermediaries (taking into account that bond and consumption prices are similar in the regulated and unregulated economies). The Figure also shows that consumption is less volatile overall with the constant taxes, which suggests that the 0.1 percent welfare gain that these taxes produce is due to both lower probabilities of Sudden Stops and binding credit constraints and a smoother consumption process.

Figure 7 also illustrates that Sudden Stop episodes in the unregulated economy are broadly in line with the empirical regularities of Sudden Stops: Large declines in consumption, the price of nontradables and the real exchange rate, and a sizable reversal in the current account-GDP ratio. Mendoza and Rojas (2017) show that these Sudden Stops are milder than in the standard SS models but they are actually a closer quantitative match to the observed features of Sudden Stops in emerging markets. 
Figure 7: Sudden Stop Events: Unregulated Economy v. Economy with Constant Taxes
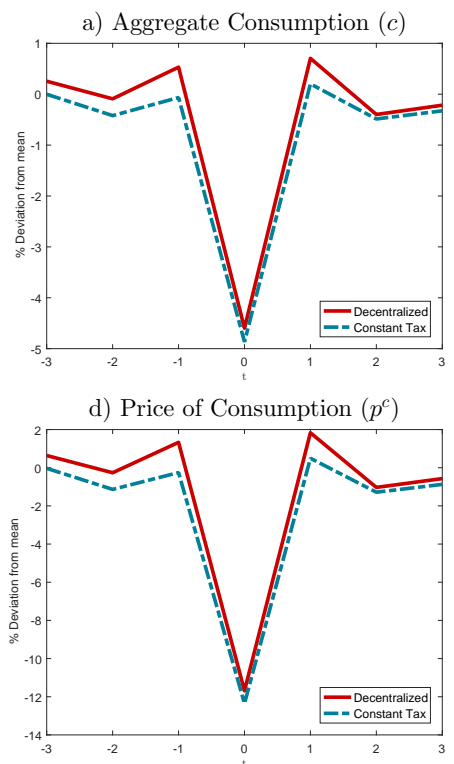

g) Expected Price of Consumption $\left(E_{t}\left[p_{t+1}^{c}\right]\right)$

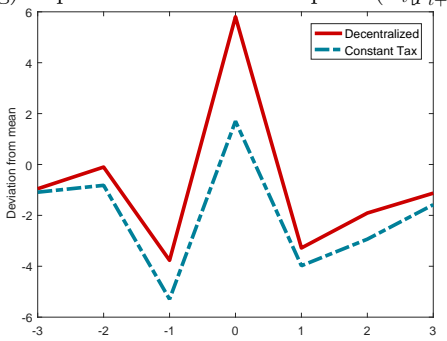

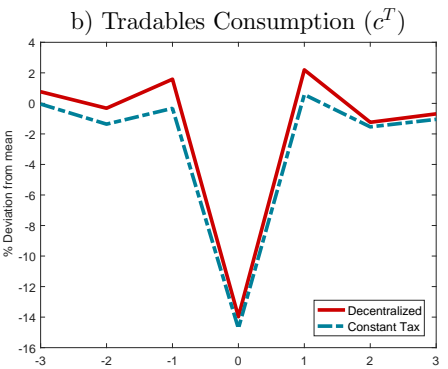

e) Bonds as Share of Tradable Inc. $\left(p^{c} b^{c /} / y^{T}\right)$

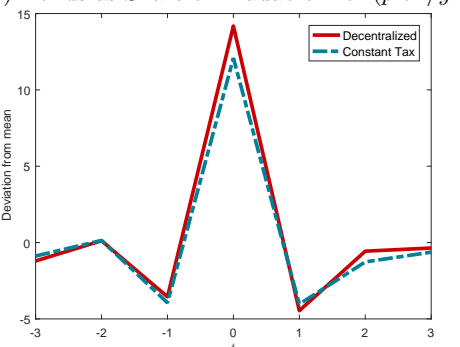

h) Ex-ante Price of Bonds $\left(q^{c}\right) / q^{*}$

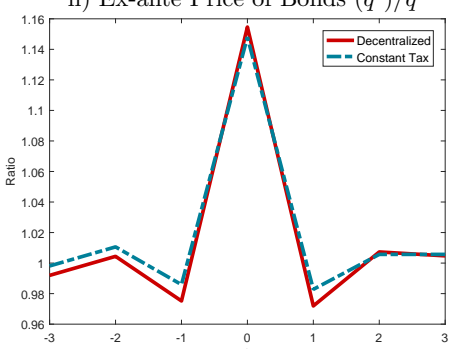

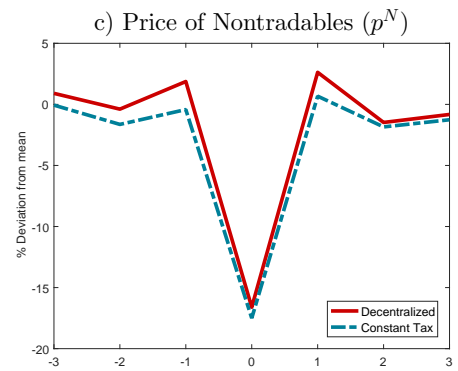
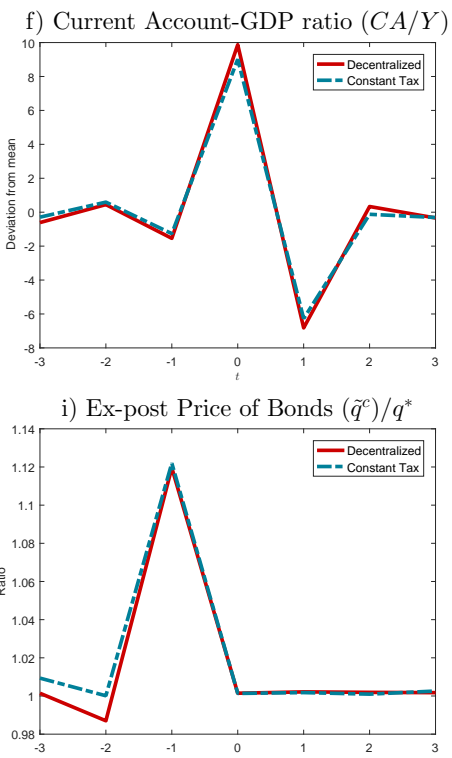

Note: All variables except those measured as output ratios are plotted as percent deviations of their corresponding long-run averages. Variables measured as output ratios are shown as differences relative to the long-run average of the corresponding ratio and expressed in percent.

\section{Conclusions}

We modified the workhorse model of Sudden Stops and macroprudential policy in emerging markets by introducing liability dollarization. Frictionless banks intermediate foreign liabilities in units of world tradable goods into domestic loans denominated in units of aggregate consumption, which is a composite good that combines tradables and nontradables. A collateral constraint limits the resources that can be generated by borrowing not to exceed a fraction of the market value of total income in the same units, so that the equilibrium relative price of nontradables enters as a determinant of borrowing capacity. Liability dollarization introduces three effects absent from the 
workhorse model that work through fluctuations in the real exchange rate: ex-post real exchange rates alter the burden of repaying existing debt, expected real exchange rates alter domestic bond prices and ex-ante real interest rates, and the negative correlation between marginal utility and real exchange rates provides a risk-taking incentive by lowering the marginal cost of borrowing.

We provided analytical results and quantitative experiments (based on a widely-used calibration for Argentina) showing that under perfect foresight only the first of the three effects operates, and two key results follow: Sudden Stops are milder than in standard SS models and multiplicity of equilibria with Sudden Stops is harder to obtain. In the SSLD model, unique equilibria are sustained for higher debt-to-income limits and the range of income levels that support multiplicity is narrower. Quantitatively, multiplicity in the SSLD model requires particular preference parameters that deviate from typical calibrations, much higher limits in debt-to-income ratios than those used in standard Sudden Stops models, and even then it is present for significantly narrower income ranges.

We also conducted a normative analysis of the optimal financial policy of a constrained-efficient regulator acting under commitment. The competitive equilibrium is distorted by two pecuniary externalities: First, the macroprudential externality typical of standard Sudden Stops models, which is present at date $t$ only when the credit constraint is expected to bind with some probability at $t+1$, because the planner internalizes the effects of the date-t borrowing decision on the size of the $t+1$ crash in collateral values. Second, an intermediation externality induced by the three effects of liability dollarization, which is present regardless of the credit constraint, because private agents do not internalize the effects of their borrowing decisions on actual and expected real exchange rates. Optimal policy tackles both externalities, but is also time-inconsistent: At date $t$, the planner has the incentive to pledge higher consumption for $t+1$ to create expectations of real appreciation and reduce interest rates, but ex-post at $t+1$ an appreciated real exchange rate is undesirable because it increases the private agent's burden of debt repayment. Moreover, decentralizing this optimal policy does not justify the use of capital controls, because capital controls and domestic debt taxes play equivalent roles. Both are needed only to alter the marginal cost of borrowing of private agents, regardless of the source of credit. In addition, the rule governing optimal effective debt taxes is a complex, non-linear rule. 
Since the optimal policy is complex and lacks credibility, we examined the potential for constant tax rates on capital inflows and domestic debt to produce welfare-improving outcomes relative to the unregulated competitive equilibrium. If the budgetary implications of capital controls are charged to private agents instead of banks, there can be a role for capital controls because they can alter borrowing capacity, whereas domestic debt taxes cannot. Quantitatively, the equivalence between capital controls and domestic debt taxes reappears at relatively high values of effective debt taxes, and for low values of effective debt taxes, welfare is higher when capital controls are set at lower rates than domestic debt taxes. The welfare-maximizing constant taxes are in the region where the two instruments are not equivalent, yielding a 2 percent debt tax v. a 0.5 percent tax on capital inflows. However, there is only a modest gain in welfare of 0.1 percent, which is largely due to a reduced frequency of Sudden Stops and binding credit constraints, while macro dynamics around Sudden Stops do not improve markedly, and in fact consumption and price declines are slightly larger when a Sudden Stop hits. These results also show that quantitative evaluation of the policy mix of debt taxes and capital controls is critical, because slight variations can produce regulated environments that leave private agents significantly worse off than in the unregulated economy.

An important limitation of our analysis is that it abstracted from modeling frictions in financial intermediation. We focused only on the effects of liability dollarization on domestic non-financial private agents, which had not been studied before, but in an environment in which risk-neutral banks are nearly frictionless and yield a simple no-arbitrage condition for pricing domestic nonstate-contingent debt. Further research should follow the earlier literature on liability dollarization and emerging markets crises to introduce more significant frictions in financial intermediation, and in particular the possibility of bankruptcy and/or non-neutral bank balance sheet effects as a result of the kind of real-exchange-rate fluctuations we examined here. 


\section{References}

Benigno, G., Chen, H., Otrok, C., Rebucci, A., and Young, E. R. (2016). 'Optimal capital controls and real exchange rate policies: A pecuniary externality perspective'. Journal of Monetary Economics, vol. 84, 147-165.

Bianchi, J. (2011). 'Overborrowing and Systemic Externalities in the Business Cycle'. American Economic Review, vol. 101, no. 7, 3400-3426.

Bianchi, J., Liu, C., and Mendoza, E. (2016). 'Fundamentals News, Global Liquidity and Macroprudential Policy'. Journal of International Economics, vol. 99, no. 1, 2-15.

Bianchi, J. and Mendoza, E. G. (2017). 'Optimal Time-Consistent Macroprudential Policy'. Journal of Political Economy. Forthcoming.

Calvo, G. (2002). “"On dollarization”'. Economics of Transition, vol. 10, no. 2, 393-403.

Céspedes, L., Chang, R., and Velasco, A. (2004). 'Balance Sheets and Exchange Rate Policy'. American Economic Review, vol. 94, no. 4, 1183-1193.

Choi, W. and Cook, D. (2004). 'Liability dollarization and the bank balance sheet channel'. Journal of International Economics, vol. 64, no. 2, 247-275.

Díaz-Alejandro, C. F. (1965). Exchange-rate devaluation in a semi-industrialized country: the experience of Argentina, 1955-1961. Cambridge, Mass.: MIT Press.

Eichengreen, B. and Hausmann, R. (1999). 'Exchange rates and financial fragility'. NBER Working Paper No. 7418.

Hernández, J. and Mendoza, E. (2017). 'Optimal v. simple financial policy rules in a production economy with "liability dollarization"'. Ensayos sobre Política Económica, vol. 35, no. 82, 25-39.

Korinek, A. (2011). 'The new economics of prudential capital controls: A research agenda'. IMF Economic Review, vol. 59, no. 3, 523-561.

Lane, P. and Milesi-Ferretti, G. (2001). 'The External Wealth of Nations: Measures of Foreign Assets and Liabilities for Industrial and Developing Countries'. Journal of International Economics, vol. 55, no. 2, 263-294. 
Ljungqvist, L. and Sargent, T. (2004). Recursive macroeconomic theory. MIT press.

Mendoza, E. (2002). 'Credit, prices, and crashes: Business cycles with a sudden stop'. In 'Preventing Currency Crises in Emerging Markets', pages 335-392. University of Chicago Press.

Mendoza, E. (2005). 'Real Exchange Volatility and the Price of Nontradables in Sudden-Stop Prone Economies'. Economia, pages 103-148. Fall.

Mendoza, E. and Rojas, E. (2017). 'Liability Dollarization, Sudden Stops \& Optimal Financial Policy'. Mimeo.

Mendoza, E. G. (2010). 'Sudden Stops, Financial Crises, and Leverage'. The American Economic Review, vol. 100, no. 5, 1941-1966.

Mendoza, E. G. (2016). 'Macroprudential Policy: Promise and Challenges'. NBER Working Paper No. 22868 .

Obstfeld, M. and Rogoff, K. (1996). Foundations of International Macroeconomics. Cambridge, Mass.: MIT Press.

Salter, W. (1959). 'Internal and External Balance: The Role of Price and Expenditure Effects'. Economic Record, vol. 35, no. 71, 226-238.

Schmitt-Grohé, S. and Uribe, M. (2017). 'Adjustment to small, large, and sunspot shocks in open economies with stock collateral constraints'. Ensayos sobre Política Económica, vol. 35, no. 82, $2-9$.

Schmitt-Grohé, S. and Uribe, M. (2018). 'Multiple Equilibria in Open Economy Models with Collateral Constraints: Overborrowing Revisited'. Mimeo, Columbia University.

Swan, T. (1960). 'Economic Control in a Dependent Economy'. Economic Record, vol. 36, no. 73, $51-66$.

Tauchen, G. and Hussey, R. (1991). 'Quadrature-Based Methods for Obtaining Approximate Solutions to Nonlinear Asset Pricing Models'. Econometrica, vol. 59, 371-396. 


\section{Appendix: Properties of the $\mathrm{BB}^{S S L D}$ Curve}

The $\mathrm{BB}^{S S L D}$ curve determines the value of $p^{N}$ that corresponds to a value of $c^{T}$ such that both the resource and the collateral constraint hold with equality (see equation (13) in the text). Formally, the $\mathrm{BB}^{S S L D}$ curves is given by the following function:

$$
p^{N}\left(c^{T}\right)=\frac{c^{T}-(1+\kappa) y^{T}-p^{c}\left(c^{T}\right) b^{c}}{\kappa \bar{y}^{N}}
$$

We omit time subscripts for simplicity, but notice $b^{c}$ corresponds to the outstanding debt at the beginning of the period. Given the parametric restrictions on $c^{T}, \kappa, y^{T}, \bar{y}^{N}$ and $b^{c}$, the fact that $p^{c}\left(c^{T}\right)$ is continuous implies that the $\mathrm{BB}^{S S L D}$ curve is continuous.

The horizontal intercept of the $\mathrm{BB}^{S S L D}$ curve is found by evaluating the above expression when $p^{N}=0$. Using equation (3) to determine the consumption price index when $p^{N}=0$, it follows that the intercept is the value of tradables consumption such that $c^{T}=(1+\kappa) y^{T}+\omega^{\frac{1}{\eta}} b^{c}$.

To obtain the slope of the $\mathrm{BB}^{S S L D}$ curve, we take the first derivative of the above expression, which yields $\frac{\partial p^{N}}{\partial c^{T}}=\frac{1-\frac{\partial p^{c}}{\partial c^{T}} b^{c}}{\kappa \bar{y}^{N}}$. The sign of the slope depends on the signs of $\frac{\partial p^{c}}{\partial c^{T}}$ and $b^{c}$. Using equation (3), it follows that because of the CES structure of preferences, $\frac{\partial p^{c}}{\partial c^{T}}=(1+$ $\eta) \frac{1-\omega}{\omega}\left[\omega+(1-\omega)\left(c^{T}\right)^{\eta}\right]^{\frac{1}{\eta}}\left(c^{T}\right)^{\eta-1}>0$. Moreover, since we are interested in economies with debt $\left(b^{c}<0\right)$, it follows that $\frac{\partial p^{N}}{\partial c^{T}}>0$. Hence, the $\mathrm{BB}^{S S L D}$ curve is increasing in $c^{T}$

To determine whether the $\mathrm{BB}^{S S L D}$ curve is concave or convex, we analyze its second derivative, which is the following:

$$
\frac{\partial^{2} p^{N}}{\partial c^{T^{2}}}=-\frac{\frac{\partial^{2} p^{c}}{\partial c^{T^{2}}} b^{c}}{\kappa \bar{y}^{N}}
$$

The sign of this derivative is the same as the sign of the second derivative of $p^{c}$ with respect to $c^{T}$. This derivative can be expressed as:

$$
\frac{\partial^{2} p^{c}}{\partial c^{T^{2}}}=(1+\eta) \frac{1-\omega}{\omega}\left(\omega+(1-\omega)\left(c^{T}\right)^{\eta}\right)^{\frac{1}{\eta}}\left(c^{T}\right)^{2(\eta-1)}\left[\frac{1-\omega}{\omega+(1-\omega)\left(c^{T}\right)^{\eta}}+(\eta-1)\left(c^{T}\right)^{-\eta}\right]
$$

All the terms in the right-hand-side of this expression are positive, except for the last term in square 
brackets, which has an ambiguous sign. Hence, the sign of this derivative is determined by the sign of the term $\left[\frac{1-\omega}{\omega+(1-\omega)\left(c^{T}\right)^{\eta}}+(\eta-1)\left(c_{T}\right)^{-\eta}\right]$. We can characterize the conditions determining the sign of this term by first reducing it to this expression:

$$
\left[\frac{1}{\tilde{\omega}+\left(c^{T}\right)^{\eta}}+\frac{\eta-1}{\left(c^{T}\right)^{\eta}}\right]
$$

where we used the definition $\tilde{\omega} \equiv \omega /(1-\omega)$. Analyzing this expression, it follows that:

$$
\left[\frac{1}{\tilde{\omega}+\left(c^{T}\right)^{\eta}}+\frac{\eta-1}{\left(c^{T}\right)^{\eta}}\right] \gtreqless 0 \quad \Leftrightarrow \quad \eta \gtreqless \frac{\tilde{\omega}}{\tilde{\omega}+\left(c^{T}\right)^{\eta}}
$$

Notice the expression in the right-hand-side of the last inequality is always a positive fraction, but its magnitude varies with $c^{T}, \omega$ and $\eta$, which is what makes the direction of the inequality ambiguous. Still, given that $\eta>-1$ from the CES functional form, and that $c^{T}>0$ and $0<\omega<1$, we can establish the following three results:

1. The $p^{c}$ and $B B^{S S L D}$ functions are strictly concave when the elasticity of substitution betwen tradables and nontradables is greater or equal to 1 : If $-1<\eta \leq 0$ (i.e. $1 /(1+\eta) \geq 1$ ) then $\eta<\frac{\tilde{\omega}}{\tilde{\omega}+\left(c^{T}\right)^{\eta}}$, and hence $\left[\frac{1}{\tilde{\omega}+\left(c^{T}\right)^{\eta}}+\frac{\eta-1}{\left(c^{T}\right)^{\eta}}\right]<0$ and thus both $p^{c}$ and $B B^{S S L D}$ are strictly concave, for any positive $c^{T}, \omega$.

2. The $p^{c}$ and $B B^{S S L D}$ functions are strictly convex when the elasticity of substitution betwen tradables and nontradables is less or equal than 1/2: If $\eta \geq 1$ (i.e. $1 /(1+\eta) \leq 1 / 2)$ then $\eta>\frac{\tilde{\omega}}{\tilde{\omega}+\left(c^{T}\right)^{\eta}}$, and hence $\left[\frac{1}{\tilde{\omega}+\left(c^{T}\right)^{\eta}}+\frac{\eta-1}{\left(c^{T}\right)^{\eta}}\right]>0$ and both $p^{c}$ and $B B^{S S L D}$ are strictly convex, for any positive $c^{T}, \omega$.

3. The $p^{c}$ and $B B^{S S L D}$ functions are concave (convex) for sufficiently low (high) $c^{T}$ when the elasticity of substitution is between 1/2 and 1: If $0<\eta<1$ (so that $1 / 2<1 /(1+\eta)<1$ ), the sign of $\left[\frac{1}{\tilde{\omega}+\left(c^{T}\right)^{\eta}}+\frac{\eta-1}{\left(c^{T}\right)^{\eta}}\right]$ changes from negative to positive as $c^{T}$ rises. Around $c^{T}=0$ we obtain $\eta<\frac{\tilde{\omega}}{\tilde{\omega}+\left(c^{T}\right)^{\eta}}=1$ and as $c^{T}$ increases $\frac{\tilde{\omega}}{\tilde{\omega}+\left(c^{T}\right)^{\eta}}$ falls. Hence, near $c^{T}=0$ the derivatives are negative and the curves are concave. By continuity, for sufficiently low $c^{T}$ the curves are concave, and for sufficiently high $c^{T}$ the curves turn convex. 
Bianchi (2011) notes that estimates of the elasticity of substitution in tradables and nontradables consumption for emerging markets are in the $[.4, .83]$ interval. Hence, most of this range falls in the region where the third result above applies. Quantitatively, however, in our baseline calibration for the perfect-foresight experiments taken from Bianchi's work (which uses $\eta=0.205,1 /(1+\eta)=0.83$ ) and for other exercises using reasonable values of $b^{c}$ and $y^{T}$ and any $0<\eta<1$, we found that $\mathrm{BB}^{S S L D}$ is either convex or nearly linear, except for a slightly concave segment for very low $c^{T}$. In all of these experiments, the concavity is visible only for $c^{T}<0.05$ compared with a perfect-foresight unconstrained equilibrium of $c^{T}=0.92$ using our baseline calibration, or a Sudden Stop outcome of $c^{T}=0.83$ for a wealth-neutral negative shock of nearly 20 percent from an initial income of $y^{T}=1$. Hence, assuming convex or nearly linear $\mathrm{BB}^{S S L D}$ curves when the elasticity of substitutions is less than unitary is innocuous. 